Published in final edited form as:

Nature. 2019 February ; 566(7743): 249-253. doi:10.1038/s41586-019-0899-7.

\title{
Interleukin-22 protects intestinal stem cells against genotoxic stress
}

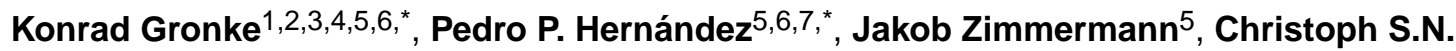 \\ Klose $^{1,5,8}$, Michael Kofoed-Branzk ${ }^{1,2,3,4,5,6}$, Fabian Guendel ${ }^{1,2,3,4,5}$, Mario Witkowski ${ }^{1,2,3,4}$, \\ Caroline Tizian ${ }^{1,2,3,4}$, Lukas Amann ${ }^{5}$, Fabian Schumacher ${ }^{9,10}$, Hansruedi Glatt ${ }^{11,12}$, \\ Antigoni Triantafyllopoulou ${ }^{13,14}$, and Andreas Diefenbach ${ }^{1,2,3,4,5}$ \\ ${ }^{1}$ Laboratory of Innate Immunity, Department of Microbiology, Infectious Diseases and \\ Immunology, Charité - Universitätsmedizin Berlin, Germany \\ ${ }^{2}$ Berlin Institute of Health (BIH), Berlin, Germany \\ ${ }^{3}$ Mucosal and Developmental Immunology, Deutsches Rheuma-Forschungszentrum, Berlin, \\ Germany \\ ${ }^{4}$ Department of Medical Microbiology and Hygiene, University Medical Centre, University of \\ Mainz, Mainz, Germany \\ ${ }^{5}$ Department of Medical Microbiology, University of Freiburg, Germany \\ ${ }^{6}$ Max-Planck Institute for Immunobiology and Epigenetics, Freiburg, Germany \\ ${ }^{7}$ Institute Pasteur, Macrophages and Development of Immunity, Paris, France \\ 8 Jill Roberts Institute for Research in Inflammatory Bowel Disease, Joan and Sanford I. Weill \\ Department of Medicine, Department of Microbiology and Immunology, Weill Cornell Medicine, \\ Cornell University, New York, NY 10021, USA \\ ${ }^{9}$ Department of Nutritional Toxicology, Institute of Nutritional Science, University of Potsdam, \\ Nuthetal, Germany \\ ${ }^{10}$ Department of Molecular Biology, University of Duisburg-Essen, Essen, Germany
}

Users may view, print, copy, and download text and data-mine the content in such documents, for the purposes of academic research, subject always to the full Conditions of use:http://www.nature.com/authors/editorial_policies/license.html\#terms

Correspondence and requests for materials should be addressed to A.D. (andreas.diefenbach@charite.de).

These authors contributed equally to the reported work.

Data availability

RNA-Seq data is available at the ArrayExpress (http://www.ebi.ac.uk/arrayexpress/) with the accession number E-MTAB-6723. All datasets generated and/or analysed during the current study are presented in this published article, the accompanying Source Data or Supplementary Information files, or are available from the corresponding author upon reasonable request.

Author Contribution

K.G and P.H. carried out most experiments and analyzed the data. J.Z., M.K-B., F.G-R., M.W., C.T., L.A., and A.T. helped with experiments and analysis. C.S.N.K. generated II22ra 1 fl/fl mice. F.S. and H.G. provided 1-MIM-OH and performed LC-MS/MS analyses. K.G., P.H. and A.D. designed the experiments and analyzed data. A.D. directed the research and wrote the manuscript with input from co-authors.

Author Information

Reprints and permissions information is available at www.nature.com/reprints. RNA-seq data is available at the ArrayExpress (http:// www.ebi.ac.uk/arrayexpress/) with the accession number E-MTAB-6723.

The authors declare no competing financial interests. 
${ }^{11}$ German Institute of Human Nutrition Potsdam-Rehbruecke (DIfE), Germany

${ }^{12}$ Department Food Safety, Federal Institute for Risk Assessment, Berlin

${ }^{13}$ Department of Rheumatology and Clinical Immunology, Charité - Universitätsmedizin Berlin, Germany

${ }^{14}$ Innate Immunity in Rheumatic Diseases, Deutsches Rheuma-Forschungszentrum, Berlin, Germany

Environmental genotoxic factors pose a serious and constant peril to the genomic integrity of cells at barrier surfaces with the environment. They can induce mutations that, if they occur in epithelial stem cells, contribute to malignant transformation and cancer development1-3. Genome integrity in epithelial stem cells is closely guarded by an evolutionary conserved, cellular response pathway, the DNA damage response (DDR). The DDR culminates in either transient cell cycle arrest and DNA repair or elimination of damaged cells by apoptosis4,5. Here we show, that the cytokine interleukin (IL-)22 produced by group 3 innate lymphoid cells (ILC3) and $\gamma \delta$ T cells is an important rheostat of the DDR machinery in intestinal epithelial stem cells. Using a new mouse model allowing for the sporadic inactivation of the IL-22 receptor in colon epithelial stem cells, we demonstrate that IL-22 is required for an effective initiation of the DDR following DNA damage. In consequence, stem cells deprived of IL-22 signals and exposed to carcinogens escaped DDR-controlled apoptosis, contained more mutations, and were more likely to give rise to colon cancer. We identified metabolites of glucosinolates, a group of phytochemicals contained in cruciferous vegetables, to be an commonplace source of genotoxic stress in intestinal epithelial cells. Glucosinolate metabolites are ligands of the aryl hydrocarbon receptor (AhR)6 and AhR signaling in ILC3 and $\gamma \delta \mathrm{T}$ cells controlled their production of IL-22. Mice fed with diets deprived of glucosinolates produced only very low levels of IL-22 and, consequently, the DDR in epithelial cells of mice on a glucosinolate-free diet was crippled. Collectively, we identify a homeostatic network protecting stem cells against perils to their genome integrity by AhRmediated "sensing" of genotoxic components contained in diets. AhR signaling in turn ensures on-demand production of IL-22 by innate lymphocytes directly regulating components of the DDR in epithelial stem cells.

To model colitis-associated colon cancer (CAC), we challenged mice with the procarcinogen azoxymethane (AOM), and then treated with dextran sodium sulfate (DSS) resulting in intestinal inflammation fueling tumor growth. AOM is an alkylating agent that generates mutagenic $O^{6}$-methylguanine $\left(O^{6} \mathrm{meG}\right)$ adducts in DNA that lead to $O^{6} \mathrm{meG}$ :T mispairings and eventually to mutations7. These mutations often affect the glycogen synthase kinase (GSK)-3 $\beta$ phosphorylation site in exon 3 of the $\beta$-catenin gene similar to the mutations $8-10$ found in the majority of human colon cancers. Mice genetically and constitutively lacking IL-22 developed more tumors11 (Extended Data Fig. 1a,b), that were mainly found in the distal part of the colon (Extended Data Fig. 1c). IL-22 is a cytokine selectively acting on non-hematopoietic cells including epithelial stem cells 12 . While the results may suggest that IL-22 restrains tumor development, these data were difficult to interpret since $I / 22^{/-}$mice have dysbiotic changes in microbial communities 13 and show 
increased inflammation11 after DSS application (Extended Data Fig. 1d-f). Thus, the enhanced inflammation itself could explain the higher number of tumors in $I 122^{/-}$mice.

II $22^{/-}$mice also developed more tumors when treated with AOM injections only (Fig. 1a). To differentiate direct effects of IL-22 signaling on tumor transformation in colon stem cells from confounding differences in inflammation, microbiota, and/or other stem cell extrinsic factors inherent to the comparison of mutant and wildtype mice, we conceived a mouse model allowing for the inducible and sporadic deletion of the gene encoding IL-22 receptor a1 (II22raI) in intestinal epithelial stem cells (Fig. 1b, Extended Data Fig. 1g), the primary target of carcinogenesis 14 . To achieve this, we first generated II22 $\mathrm{ra} \mathrm{f}^{\mathrm{fl} / \mathrm{fl}}$ mice (Extended Data Fig. $2 \mathrm{a}-\mathrm{g}$ ) and crossed these to $\operatorname{Lgr}_{5} 5^{\mathrm{CreER} \text { 2/+ }}$ mice allowing for tamoxifen-inducible Cre activity in crypt-based columnar stem cells 15 . To report Cre activity and gene inactivation, Il22 $r a I^{\mathrm{fl} / f 1} ; \operatorname{Lgr}{ }^{\mathrm{CreERt} 2 /+}$ mice were further mated to Rosa26R-Confetti mice, containing four colors that are stochastically activated after Cre-mediated removal of a transcriptional roadblock16. After tamoxifen application, we targeted on average 15-30\% of crypts (Fig. 1c) and the fraction of crypts with one or more colors was not affected by II22ra1 expression (Extended Data Fig. 2h,i). In contrast to the comparison of mutant and wildtype mice (Extended Data Fig. 1d), we did not detect any differences in DSS-induced weight loss between $I / 22 \mathrm{ra} I^{\mathrm{fl} / \mathrm{fl}} ; \operatorname{Lgr} 5^{\mathrm{CreERt} 2 /+} ; R 26 R$-Confetti and II22raf ${ }^{\mathrm{fl} /+} ; \operatorname{Lgr}^{5 \mathrm{CreERt} 2 /+} ; R 26 R$-Confetti mice (Extended Data Fig. $2 \mathrm{j}$ ). Importantly, Confetti + tumors from II22ra $I^{\mathrm{fl} / \mathrm{fl}} ; \mathrm{Lgr} 5^{\mathrm{CreERt} /+} ; R 26 R$-Confetti mice did not express IL-22Ra1 whereas Confetti ${ }^{-}$tumors in the same mouse were IL-22Ra1-positive (Extended Data Fig. 3 a-e). This approach allowed us to interrogate IL-22-dependent programs in stem cells within the same mouse by creating a mosaic of IL-22Ra1 ${ }^{+}$and IL-22Ra1- crypts (Fig. 1b).

Considering the labelling efficiency (Fig. 1c, Extended Data Fig. 2h,i), we would expect $15-30 \%$ of Confetti ${ }^{+}$tumors which is what we observed in mice having one functional allele of II22ral (Fig. 1d). In striking contrast, the fraction of Confetti ${ }^{+}$tumors in mice with sporadic inactivation of the II22ral gene was substantially increased, demonstrating that absence of IL-22 signaling in colon epithelial cells pre-disposes them for tumor development (Fig. 1d-f). In the colon, roughly half of the IL-22 producers were $\mathrm{CD} 4^{+} \mathrm{T}$ cells, a third ILC3 and ca. $6 \%$ each, Foxp $3^{+} \mathrm{CD}^{+} \mathrm{T}$ cells and $\gamma \delta \mathrm{T}$ cells (Extended Data Fig. $4 \mathrm{a}$ ). ILC3 were the dominant source of IL-22 in the small intestine (Extended Data Fig. 4b). Less sheltered mice showed a larger fraction $(79-88 \%)$ of $\mathrm{CD}^{+} \mathrm{T}$ cells among IL-22 producers (Extended Data Fig. 4c). Collectively, the data demonstrate that IL-22 signaling in colon epithelial cells is a significant barrier to tumor development.

Stem cells are the origin of cancer4,14. IL-22 is continuously produced at the steady-state17 but the IL-22-controlled transcriptional networks in colon stem cells are unknown. Using RNA-seq, we found that during the steady-state 350 genes (with FC $>2$ ) were changed in expression between Lgr5 $5^{+}$colon stem cells of $I 122^{+/+}$and $I 122^{-/}$mice (Extended Data Fig. $5 \mathrm{a}, \mathrm{b})$. Gene Set Enrichment Analysis (GSEA) revealed, that stem cells from $\mathrm{II22^{- }}$ mice were depleted of transcripts associated with 'DNA Repair' (Fig. 2a) and 'DNA doublestrand break processing' (Extended Data Fig. 5c). Considering these biological pathways, we performed RNA-seq of sorted colonic $\mathrm{Lgr}^{+}$stem cells from $I 122^{+/+}$and $I 122^{-/}$mice 24 hours after inducing DNA double strand breaks when the cellular response to DNA damage 
was maximal (Extended Data Fig. 5d). GSEA of the expressed genes showed significant enrichment of gene signatures such as 'Hallmark Apoptosis' and 'DNA damage response effector genes' in $\mathrm{Lgr}^{+}$stem cells from $\mathrm{Il22^{+/+ }}$ but not from $\mathrm{Il22^{/- }}$ mice (Fig. 2b, Extended Data Fig. 5e). IL-22BP is an antagonist of IL-22 produced to blunt excessive and potentially pathologic IL-22 production11. IL-22BP production was reduced following DNA damage allowing for higher concentrations of bioactive IL-22 (Extended Data Fig. 5f). These data indicate that stem cells deprived of IL-22 signals lack transcriptional signatures of the DDR and DNA repair pathways.

To pinpoint the IL-22-dependent processes within the DDR, we performed a systematic analysis of critical checkpoints. Expression of MRN complex genes (Mre11, Rad50, Nbn), which sense DNA damage, was independent of IL-22 (Extended Data Fig. 5g). The MRN complex recruits and activates a group of kinases (i.e., ATM, ATR, DNA-PK) which initiate the DDR cascade and are expressed in almost all living cells for an immediate response to genotoxic stress 18. We found a reduction of Atm expression in colon stem cells from $1122^{-1-}$ mice already in the absence of genotoxic stress (Fig. 2c,d, Extended Data Fig. 5h,6a). Atm is a STAT3 target gene19 and IL-22 induces STAT3 signaling in epithelial cells20. STAT3 ChIP using primers for three STAT3 binding sites in the Atm gene regulatory elements (Extended Data Fig. 6b) revealed reduced STAT3 occupancy at all three binding sites in epithelial cells from $I / 22^{--}$mice during the steady-state (Extended Data Fig. 6c). Exogenous in vivo application of IL-22 significantly enhanced STAT3 binding (Extended Data Fig. 6c) and increased ATM levels in colon epithelial stem cells (Fig. 2d). After DNA damage, ATM phosphorylates histone variant $\mathrm{H} 2 \mathrm{AX}$ (referred to as $\gamma \mathrm{H} 2 \mathrm{AX}$ ) which flanks the break site 21 . While $I 122^{+/+}$mice showed maximal $\gamma \mathrm{H} 2 \mathrm{AX}$ levels in colon crypts 8 hours after irradiation, there was virtually no increase in $I 122^{-/}$or II22ra $I^{\mathrm{fl} / \mathrm{fl}}$; Vill-Cre mice at any time point investigated (Fig. 2e,f and Extended Data Fig. 6d,e). H2AX protein levels did not differ between $I I 22^{+/+}$and $I 122^{/-}$mice (Extended Data Fig. 6f). While we used irradiation here as the paradigm to cause double strand DNA breaks, AOM treatment led to the same extent of IL-22-dependent $\gamma \mathrm{H} 2 \mathrm{AX}$ formation (Extended Data Fig. 6g,h). Collectively, our data demonstrate that during the steady-state IL-22 regulates the expression of ATM via STAT3 in colon epithelial stem cells, supervising the initiation of the DDR following genotoxic stress.

Phosphorylation of p53 and SMC (structural maintenance of chromosome) proteins, both direct targets of ATM4,5,18, was reduced in colon epithelial cells of irradiated $I 122^{-1-}$ mice (Extended Data Fig. 7a). Based on our RNA-seq data, expression of various p53 target genes (e.g., p21, Puma, hnRNPK, Susd6, Btg2 and Mdm2)22,23 was diminished in colon stem cells of $I 122^{/-}$mice (Fig. 2a,b, Extended Data Fig 5b). In particular, $p 21$, a cell cycle arrest gene, and Puma, a pro-apoptotic gene24 were not efficiently induced in $I 122^{\prime-}$ mice following irradiation (Fig. 3a,b, Extended Data Fig. 7b) or AOM treatment (Extended Data Fig. 7c). Increased expression of these genes after DNA damage required IL-22 signaling in epithelial cells as documented in mice with deletion of IL-22Ra1 or STAT3 in all intestinal epithelial cells (Fig. 3b, Extended Data Fig. 7d). Exogenous application of IL-22 rescued Puma levels in colon stem cells depending on IL-22R expression (Fig. 3c). 
We hypothesized that colon stem cells experiencing DNA damage in the absence of IL-22 signals, do not undergo PUMA-mediated apoptosis or p21-controlled cell cycle arrest. Genetic inactivation of IL-22Ra1 in epithelial cells or antibody-mediated neutralization of IL-22 resulted in a lower fraction of apoptotic (i.e., cleaved (c)Caspase $3^{+}$) $\mathrm{Lgr}^{+}$stem cells in colon crypts following irradiation (Fig. 3d,e, Extended Data Fig. 7e-g, and 8a-d). Using sporadic inactivation of IL-22Ra1 in colon epithelial stem cells, we found a highly significant reduction of apoptosis in IL-22Ra1-deficient crypts (i.e., Confetti ${ }^{+}$crypts) compared to IL-22Ra1-proficient crypts (i.e., Confetti ${ }^{-}$) within the same mouse (Fig. 3f,g). Inhibition of apoptosis with zVAD, a pan-caspase inhibitor, in $\mathrm{Il}^{+/ /+}$mice led to significantly increased numbers of tumors comparable to $I 122^{--}$mice (Fig. $3 \mathrm{~h}$ ). These data demonstrate that the reduced rate of apoptosis observed after DNA damage in IL-22deprived colon stem cells may explain the higher number of tumors.

Cells that continue to cycle in the presence of DNA breaks are prone to mitotic defects leading to the formation of micronuclei, a sign of genomic instability. Colonic epithelial cells of irradiated $I 122^{--}$mice showed increased numbers of micronuclei when compared to wildtype controls (Fig. 3i). Conversely, treatment of an intestinal epithelial cell line with IL-22 reduced the numbers of micronuclei after irradiation (Extended Data Fig. 8e). IL-22 has also been described as promoting proliferation of damaged stem cells 12 and sustaining proliferation of already transformed cells 25 . We found an increase in proliferation after DNA damage in $I 122^{+/+}$mice which was absent in II22/- mice (Extended Data Fig. 8f). The DDR is a powerful cellular program that prevents accumulation of mutations after genotoxic stress. We isolated colon epithelial cells from mice eight weeks after AOM administration and quantified the frequency of exon 3 mutations in the Ctnnb1 gene which are strongly associated with various forms of human cancer including colon cancer9,10. Colon epithelial cells from $I I 22^{/-}$mice accumulated a much higher frequency of Ctnnb1 mutations than cells from $\mathrm{II}_{22^{+/+}}$mice (Fig. 3j). Thus, IL-22, a cytokine produced by lymphocytes, acts as an important, epithelial cell-extrinsic regulator of the DDR in colon stem cells preventing the accumulation of potentially dangerous mutations.

Mutations accumulate in colon stem cells during life, partially due to environmental genotoxic compounds3. Cruciferous vegetables of the Brassicaceae family contain large amounts of a group of phytochemicals referred to as glucosinolates6, some of their metabolites are potent genotoxins26. For example, the glucosinolate metabolite 1methoxy-3-indolylmethyl alcohol (1-MIM-OH) leads to the formation of DNA adducts and activates the DDR26 (Extended Data Fig. 9a). We applied a single dose of 1-MIM-OH by gavage and monitored the expression of PUMA and p21 (Fig. 4a, Extended Data Fig. 9b), which were induced in colon epithelial stem cells in an IL-22-dependent manner. Indole 3carbinol (I3C), a glucosinolate metabolite without DNA damaging qualities, did not trigger the DDR (Fig. 4b). Regardless of their DNA-damaging qualities, a single application of 1MIM-OH or I3C significantly increased the production of IL-22 by ILC 3 and $\gamma \delta$ T cells but not by $\mathrm{CD}^{+}{ }^{+} \mathrm{T}$ cells (Fig. 4c,d and Extended Data Fig. 9c,d). IL-10 production by FoxP3 ${ }^{+} \mathrm{T}$ cells was not affected either (Extended Data Fig. 9e). Glucosinolate-induced IL-22 expression enhanced expression of $\operatorname{Reg} 3 g$, an antimicrobial gene regulated by IL-22 (Extended Data Fig. 9f,g). 
The increase of IL-22 production in response to 1-MIM-OH or I3C required AhR expression in ILC3 and T cells (Extended Data Fig. 9h)27-29. Mice genetically lacking AhR in ILC3 and $\mathrm{T}$ cells had a phenotype comparable to IL-22-deficient mice with reduced expression of ATM (Fig. 4e), and, following genotoxic stress, with diminished phosphorylation of H2AX (Fig. 2e,f, Extended Data Fig. 6d), absent induction of p21 and PUMA expression (Fig. 4f) and reduced apoptosis of crypt-resident stem cells (Extended Data Fig. 8a,b). Importantly, IL-22 application to $A h r^{\mathrm{fl} / \mathrm{fl}} ; \operatorname{Rorc}(\gamma t)-\mathrm{Cre}^{\mathrm{Tg}}$ mice restored PUMA expression (Fig. 3c).

We wondered whether glucosinolate-deprived diets would be disadvantageous to the host to deal with consecutive genotoxic stress. We fed adult mice, either with an experimental defined diet (EDD) that lacks phytochemicals (including glucosinolates; EDD-) or with a defined diet supplemented with I3C, EDD+ (Extended Data Fig 9b). Normal mouse chow, naturally containing bioactive concentrations of AhR ligands, served as control diet (CD). Colon ILC3 and $\gamma \delta$ T cells from mice on EDD- did not produce IL-22, whereas they produced high levels of IL-22 when mice were fed EDD+ or CD (Fig. 4g and Extended Data Fig. 10a,b). Epithelial cells from mice on EDD- showed reduced expression of ATM (Fig. 4h), and, following DNA damage, a profound reduction in $\gamma \mathrm{H} 2 \mathrm{AX}$ (Fig. 4i, Extended Data Fig. 10c), in induction of $p 21$ and Puma expression (Fig. 4j) and in apoptosis observed in colon crypts (Fig. 4k, Extended Data Fig. 10d). Importantly, I3C addition to the diet restored all of these functions. Thus, AhR-mediated regulation of IL-22 provided a substantial barrier against DNA damaging agents as part of our diets.

Collectively, we uncovered a novel homeostatic control circuit by which IL-22-producing and tissue-resident innate lymphocytes regulate the response of epithelial stem cells to genotoxic dietary compounds at border surfaces with the environment, thereby effectively limiting the number of mutations (Extended Data Fig. 10e). The AhR expressed by ILC3 and $\gamma \delta$ T cells serves as a "sensor" of genotoxic phytochemicals for on-demand production of IL-22 supervising the DDR machinery in epithelial stem cells. The AhR may turn out to be an important node for cancer development as AhR signaling within epithelial cells was recently shown to reduce colon cancer development30. Finally, we expect such communication between innate lymphocytes and their tissue client cells to be operative at other border surfaces which may be exploited as an adjunctive therapy to avoid genotoxic sequelae associated with various forms of clinical therapy such as chemotherapy, radiation therapy and bone marrow transplantation.

\section{Methods (online only)}

\section{Mice}

Conventional (specific pathogen-free) C57BL/6N mice were purchased from Janvier Laboratories. $\operatorname{Lgr}_{r} 5^{\text {EGFP-IRES-CreERt2/+ }}$ (here referred to as $L g r 5^{\mathrm{CreERt} 2 /+}$ or $L g r 5^{\text {Egfp/+ }}$ mice)15, Rosa26R-Confetti16 and $\operatorname{Rorc}(\gamma t)$-Cre ${ }^{\mathrm{Tg}}$ mice 31 were purchased from Jackson Laboratories and crossed in our animal facility. $I / 22^{/-}$mice were a kind gift of JeanChristophe Renauld and Laure Dumoutier (Ludwig Institute for Cancer Research, Brussels, Belgium)32. Mice with a floxed Stat3 allele33 were kindly provided by Veronika Sexl (University of Veterinary Medicine Vienna) with permission of Valeria Poli (Universita di Torino, Torino, Italy). Villin 1-Cre ${ }^{\mathrm{Tg}}$ mice34 were kindly provided by Marc Stemmler (Max- 
Planck-Institute of Immunobiology \& Epigenetics, Freiburg, Germany) with permission of Sylvie Robine (Institute Curie, Paris, France). Mice with an IEC-specific deletion of Stat3 $\left(\right.$ Stat $3^{\mathrm{fl} / \mathrm{fl}} ;$ Vill-Cre) were generated by breeding Stat ${ }^{\mathrm{fl} / \mathrm{fl}}$ mice with Villin1-Cre ${ }^{\mathrm{Tg}}$ mice.

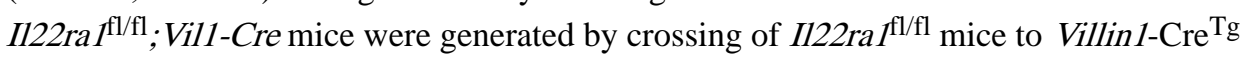
mice. $A h r^{-/-}$mice35 and $A h r^{\text {fl/fl }}$ mice 36 were kindly provided by Charlotte Esser (Leibniz Research Institute for Environmental Medicine, Düsseldorf, Germany). Ahr ${ }^{\mathrm{fl} / \mathrm{fl}} ; \operatorname{Rorc}(\gamma t)$-Cre mice were obtained by crossing $A h r^{\mathrm{fl} / \mathrm{fl}}$ mice with $\operatorname{Rorc}(\gamma t)-\mathrm{Cre}^{\mathrm{Tg}}$ mice27. To identify Lgr5 ${ }^{+}$ stem cells, we backcrossed $I I 22^{+/+}$and $I I 22^{-/-}$mice to $L g r 5^{\text {EGFP-IRES-CreERt2/+ }}$ mice (referred to as $I I 22^{-/} ; L_{g r} 5^{\text {Egfp/+ }}$ mice or $I 122^{+/+} ; L_{g r} 5^{\text {Egfp/+ }}$ mice). Mice were 8 to 10 weeks of age, unless indicated otherwise. Cohoused littermates were used as controls whenever possible. Animals were housed in accordance with the guidelines by the Federation for Laboratory Animal Science Associations and the national animal welfare body Gesellschaft für Versuchstierkunde. Experiments were in compliance with the German animal protection law (TierSchG) and were approved by the local animal care committee (G15-1-034, Landesuntersuchungsamt Rheinland-Pfalz, Koblenz).

\section{Generation of II22ra ${ }^{\mathrm{fl} / \mathrm{fl}}$ mice}

II22ra $f^{\mathrm{fl} / \mathrm{fl}}$ mice were generated using EUCOMM ES cells subclone JM8.N4 $\left(I I 22 \mathrm{ra} I^{\mathrm{tm} 1 \mathrm{a}}\right.$ (EUCOMM)Wtsi)37. In brief, a floxed II22ra1 allele was created by inserting an FRT-flanked IRES-LacZ-Neo resistance cassette into intron 1 of the II22ral gene. LoxP sites were inserted to flank exon 2 (Extended Data Fig. 2a-g). After germ-line transmission, the FRT cassette was removed by crossing to FLPe deleter mice38. For inactivation of the II22ra1 allele in intestinal stem cells, II22ra $I^{\mathrm{fl} / \mathrm{fl}} ; \operatorname{Lgr}^{\mathrm{CreERt} 2 /+} ;$ Rosa26R-Confetti mice were fed for two weeks with diets containing $400 \mathrm{mg} / \mathrm{kg}$ tamoxifen citrate (Envigo). Tamoxifen was stopped seven days before tumor induction.

\section{DNA damage}

Acute DNA damage was induced by i.p. injection of $25 \mathrm{mg} / \mathrm{kg}$ (body weight) azoxymethane (AOM) or by exposure of cells or mice to a ${ }^{137}$ Caesium (Cs) source in an OB58/905-2 irradiator (Buchler, Germany). For acute DNA damage, mice were exposed to 8Gy of irradiation if not indicated otherwise. For the analysis of IL-22 production, mice were injected with $25 \mathrm{mg} / \mathrm{kg}$ (body weight) AOM and lamina propria lymphocytes were analysed 24h later.

\section{IL-22 neutralization and reconstitution}

Monoclonal anti-IL-22 (Clone 8E11) blocking antibody was kindly provided by Genentech

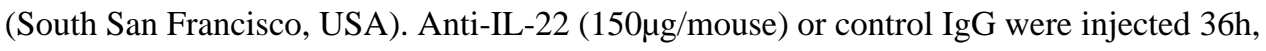
$12 \mathrm{~h}$ before and $12 \mathrm{~h}$ after inducing DNA damage. For reconstitution, mice were injected with recombinant IL-22 (400ng/mouse, Peprotech) i.p. every $8 \mathrm{~h}$ for three days prior to the damage induction and at $8 \mathrm{~h}$ and $16 \mathrm{~h}$ afterwards. Epithelial cells were isolated $24 \mathrm{~h}$ after damage. For the stimulation of ATM expression, mice were injected with recombinant IL-22 (500 ng/mouse, Peprotech) i.p. $12 \mathrm{~h}$ and $2 \mathrm{~h}$ prior to epithelial isolation. 


\section{Colitis-associated cancer}

Mice of various genotypes were co-housed and injected with $10 \mathrm{mg} / \mathrm{kg}$ body weight azoxymethane (AOM, Sigma-Aldrich) i.p. on day 1. Starting from day 7, mice were given $2 \%$ Dextrane Sulfate Sodium (DSS) in the drinking water for 7 days. The weight of the mice was monitored weekly. The approved experimental procedures limited maximal colorectal tumor burden to a $20 \%$ decrease in body weight. None of the experimental animals reached this threshold. Tumor formation was assessed starting from day 80 after AOM treatment. For AOM-only induced cancer, mice were injected three times in weekly intervals with $10 \mathrm{mg} / \mathrm{kg}$ AOM i.p.. No DSS was given in the drinking water and tumor formation was assessed 4 months after the first AOM application. For the blockade of apoptosis, a pan-Caspase inhibitor zVAD-FMK (Invivogen) was injected at $2 \mathrm{mg} / \mathrm{kg}$ i.p. daily on day 0 - day 5 , with AOM being injected on day 1 . Tumor formation was assessed on day 90 .

\section{Epithelial cell isolation and quantitative PCR}

The colon, including the anorectal section, was opened longitudinally and cleaned from feces and fat tissue. Epithelial cells were harvested by incubating the tissue for $45 \mathrm{~min}$ in Hank's Balanced Salt Solution (HBSS) supplemented with $5 \mathrm{mM}$ EDTA and $10 \mathrm{mM}$ HEPES at $37{ }^{\circ} \mathrm{C}$. Cells were pelleted and resuspended in $500 \mu \mathrm{l}$ Trizol (Life Technologies) and macerated using MP FastPrep-24 (MP Biomedicals). RNA was extracted according to the ImmGen protocol (https://www.immgen.org/Protocols/Total\%20RNA\%20Extraction $\% 20$ with\%20Trizol.pdf) and cDNA was transcribed using High Capacity cDNA Reverse Transcription Kit (Applied Biosystems). Quantitative PCR was performed using qPCR SYBR Green Master Mix (Applied Biosystems) on a 7900HT Fast Real-Time PCR System (Applied Biosystems). Primer sequences are in Supplementary Information Table 1.

\section{Lamina propria lymphocyte isolation}

Lamina propria lymphocytes were isolated as described previously39. In brief, small intestine or colon was removed and cleaned from feces and fat tissue. Peyer's patches were removed and epithelial tissue was dissociated by incubation in HBSS supplemented with $5 \mathrm{mM}$ EDTA and $10 \mathrm{mM}$ HEPES at $37^{\circ} \mathrm{C}$. Tissue was minced and subsequently digested in HBSS containing Dispase (5U/ml; BD Biosciences), collagenase D $(0.5 \mathrm{mg} / \mathrm{ml}$; Roche) and DNaseA $\left(0.5 \mathrm{mg} / \mathrm{ml}\right.$; Sigma-Aldrich) and $3 \% \mathrm{FCS}$ for $1 \mathrm{~h}$ at $37^{\circ} \mathrm{C}$. Lymphocytes were enriched using an 80/40 Percoll gradient (Sigma-Aldrich). For cytokine staining, cells were resuspended in RPMI medium with 10\% FCS, 80 $\mu \mathrm{M}$ 2-mercaptoethanol, 10mM HEPES, $1 \mathrm{mM}$ sodium pyruvate, non-essential amino acids (Gibco), 100units $/ \mathrm{ml}$ penicillin, $0.4 \mathrm{mg} / \mathrm{ml}$ gentamicin and $100 \mathrm{mg} / \mathrm{ml}$ streptomycin and $8 \mathrm{mg} / \mathrm{ml}$ glutamine and stimulated for $4 \mathrm{~h}$ at $37^{\circ} \mathrm{C}$ in the presence of brefeldin A (Sigma-Aldrich), IL-1 $\beta$ (10ng/mL, Peprotech) and IL-23 (20ng/mL, Thermo Fisher) or for IL-10 production with PMA (25ng/mL, SigmaAldrich) and ionomycin (500ng/mL, Sigma-Aldrich). Cells were fixed with FoxP3 fixation/ permeabilization kit (eBioscience) overnight and stained with fluorochrome coupled antibodies for $2 \mathrm{~h}$ at $4{ }^{\circ} \mathrm{C}$. Cells were washed and analyzed on a FACS Canto II flow cytometer (BD Biosciences)40. Data was analyzed using FlowJo Software V10.3 (Treestar). All antibodies used are listed in Supplementary Information Table 2. 


\section{Histology}

Colon was opened longitudinally and cleaned from feces and fat tissue. "Swiss rolls" were prepared by winding the tissue on a wooden toothpick and tissue was fixed for $2 \mathrm{~h}$ in $4 \%$ paraformaldehyde at $4^{\circ} \mathrm{C}$. The tissue was washed and incubated overnight in $30 \%$ sucrose in phosphate buffer. Rolls were frozen in O.C.T. Tissue Tek (Sakura) and stored at $-80^{\circ} \mathrm{C}$. For analysis, $6 \mu \mathrm{m}$ sections were cut using a CM1950 Cryotome (Leica). Sections were dried, rehydrated and blocked for $1 \mathrm{~h}$ with $10 \%$ bovine serum albumin (BSA). Primary antibodies specific for cleaved Caspase-3 (Asp175; 5A1E; Cell Signaling Technology), IL-22ra1 (496514, Thermo Fisher) and $\gamma \mathrm{H} 2 \mathrm{AX}$ (20E3; Cell Signaling Technology) in $0.1 \%$ Triton $\mathrm{X}-100$ in PBS were incubated overnight at $4^{\circ} \mathrm{C}$. Secondary (a-rabbit-Alexa555, a-rabbitAPC, a-rat-Alexa647; Life Technologies) and directly conjugated antibodies (a-EpCamAPC; eBioscience) were incubated $1 \mathrm{~h}$ at room temperature. Slides were mounted using PermaFluor Aqueous Mounting Medium (Thermo Scientific) and imaged on an AF7000 or a TCS SP5 microscope (Leica). Image analysis was done using ImageJ analysis software41. For quantification of cleaved Caspase- 3 and $\gamma \mathrm{H} 2 \mathrm{AX}$, whole colon sections were filtered for EpCam-positive cells and within these, marker-positive cells were counted. Positive cells were normalized to the total amount of epithelial cells (i.e., $\mathrm{DAPI}^{+} \mathrm{EpCam}^{+}$cells).

\section{RNA-seq analysis of $\mathrm{Lgr5}^{+}$colon stem cells}

The colon, including the anorectal section, was removed, opened longitudinally and cleaned from feces and fat tissue. Epithelial cells were harvested by incubating the tissue for $45 \mathrm{~min}$ in HBSS supplemented with $5 \mathrm{mM}$ EDTA and $10 \mathrm{mM}$ HEPES at $37^{\circ} \mathrm{C}$. Supernatant was collected, pelleted and afterwards digested for $30 \mathrm{~min}$ at $37^{\circ} \mathrm{C}$ in HBSS containing $3 \%$ FCS, Dispase ( $5 \mathrm{U} / \mathrm{ml}$; BD Biosciences), collagenase D $(0.5 \mathrm{mg} / \mathrm{ml}$; Roche) and DNaseA $(0.5 \mathrm{mg} / \mathrm{ml}$; Sigma-Aldrich). For flow cytometry analysis, cells were stained in PBS containing $2 \%$ FCS. Colon stem cells were identified as DAPI ${ }^{-} \mathrm{EpCam}^{+} \mathrm{CD}^{-} 5^{-} \mathrm{CD} 24^{\text {int }}$ $\mathrm{Lgr}^{+}$cells (Extended Data Fig. 5a), were highly purified using a FACS Aria III Cell Sorter (BD Biosciences) and taken up in Trizol (Life Technologies). RNA was extracted, and libraries were prepared with SMARTer Ultra Low Input RNA (Clontech), according to the manufacturer's instructions. Material was enriched for polyA sequences and Next Generation Single-end sequencing was done on a HiSeq 2500 machine (Illumina) with a maximal readlength of 50 bases. Bioinformatic processing was performed using the Cufflinks pipeline42. Fragments Per Kilobase Million (FPKM) values were used for transcriptional comparison. Computational processing was done using RStudio Software (The R Foundation). Genes without any mappable reads were excluded from the analysis. Gene Set Enrichment Analysis (GSEA) was done with Broad Institute GSEA Software43. Genesets were taken from MSigDB. The "DNA Damage Response Effector Genes" geneset was created from the literature4 (Extended Data Fig. 5e). Full lists of Gene Sets with expression heatmaps can be found in Supplementary Information Table 3.

\section{Western blot analysis}

Epithelial cells were harvested as described above. Cells were lysed using NP-40 lysis buffer (20 mM TRIS-HCl, $150 \mathrm{mM} \mathrm{NaCl}, 1 \%$ Triton X-100, 0.5\% NP-40, Protease \& Phosphatase Inhibitor w/o EDTA; Thermo Fisher) for $1 \mathrm{~h}$ on ice and additionally sonicated for 3 cycles 
using Bioruptor Plus (Diagenode). SDS-PAGE was performed with gels containing 5\% or $10 \%$ polyacrylamide and blotted $16 \mathrm{~h}$ with $40 \mathrm{~mA}$ on a PVDF membrane (Carl Roth). Detection antibodies p21 (F5; Santa Cruz), PUMA, p-p53 (all Abcam), Actin (AC15; Sigma-Aldrich), p-SMC (D7S8Y), mouse ATM (D2E2), SMC (8E6), $\gamma$ H2AX (D17A3) (all Cell Signaling Technology) were diluted in 5\% BSA and incubated overnight at $4{ }^{\circ} \mathrm{C}$. Secondary antibodies were coupled to HRP ( $a$-mouse-HRP, a-rabbit-HRP; Jackson Immuno Research) and visualized using enhanced chemiluminescence (PerkinElmer) and Hyperfilm (GE Healthcare). All antibodies used are listed in Supplementary Information Table 2.

\section{STAT3 ChIP}

Mice were injected $1 \mu \mathrm{g}$ recombinant IL-22 (Peprotech) or PBS i.p. $1 \mathrm{~h}$ prior to epithelial cell isolation. Epithelial cells were isolated as described above. Cells were resuspended in PBS and fixed with $0.75 \%$ paraformaldehyde. Fixation was stopped with glycine and cells were washed and lysed in 50mM Tris, 2.5mM EDTA, $0.1 \%$ NP-40 and $10 \%$ Glycerol. Nuclei were lysed in 50mM Tris, 5mM EDTA and $0.25 \%$ SDS and subsequently sonicated in a Bioruptor Plus (Diagenode). Lysates were cleared by centrifugation and stored at $-80^{\circ} \mathrm{C}$. Protein-A-coated magnetic beads (Diagenode) were blocked with yeast tRNA (Life Technologies) and BSA (New England Biolab). Nuclear lysates were split in 10\% input and 90\% immunoprecipitation solutions. The latter was incubated with a-STAT3 (C-20; Santa Cruz Biotechnology) overnight rotating at $4^{\circ} \mathrm{C}$. Protein-A coded magnetic beads were added and incubated for another $30 \mathrm{~min}$ rotating at $4^{\circ} \mathrm{C}$. Beads were purified and washed repeatedly. Bound DNA was eluted in $10 \mathrm{mM}$ TRIS, $1 \mathrm{mM}$ EDTA and $2 \%$ SDS at $37^{\circ} \mathrm{C}$ for $15 \mathrm{~min}$. De-crosslinking was performed overnight at $65^{\circ} \mathrm{C}$. RNA was removed by $1 \mathrm{~h}$ incubation with RNAse A (Peqlab) at $37^{\circ} \mathrm{C}$, followed by $1 \mathrm{~h}$ incubation with Proteinase $\mathrm{K}$ (Peqlab) at $42^{\circ} \mathrm{C}$. DNA was purified using PCR Purification Kit (Qiagen) according to the manufacturer's instructions. All antibodies used are listed in Supplementary Information Table 2.

\section{Micronucleus Assay}

IEC6 cells44 were cultured for 48h in DMEM (Life Technologies) with 10\% FCS, 80 $\mu \mathrm{M} 2-$ mercaptoethanol, 10mM HEPES, 1mM sodium pyruvate, non-essential amino acids (Gibco), 100units $/ \mathrm{ml}$ penicillin, $0.4 \mathrm{mg} / \mathrm{ml}$ gentamicin and $100 \mathrm{mg} / \mathrm{ml}$ streptomycin and $8 \mathrm{mg} / \mathrm{ml}$ glutamine and $0.1 \mathrm{U} / \mathrm{ml}$ insulin (Sigma-Adrich), with or without $100 \mathrm{ng} / \mathrm{mL}$ IL-22 (Peprotech). After culturing cells in the presence of IL-22 for three days, cells were irradiated with $2 \mathrm{~Gy}$. Afterwards they were cultured for another $48 \mathrm{~h}$ in the presence of cytochalasin B ( $4.5 \mu \mathrm{g} / \mathrm{ml}$, Sigma-Aldrich) to stop cytokinesis. Nuclei of cells that had undergone division, and the occurrence of micronuclei within these cells, were counted under a fluorescent microscope. Between 500 and 1000 Nuclei per replicate were analysed. For analysis of primary epithelium ex vivo, mice were irradiated with $2 \mathrm{~Gy}$ and epithelial cells were isolated by EDTA-based dissociation as described above. For micronucleus assessment cells were settled on glass slides and fixed for $2 \mathrm{~min}$ in ice-cold methanol. DNA was stained with DAPI (Sigma-Aldrich) and images were acquired on an Axiovert 200M microscope (Zeiss). 


\section{Ctnnb1 Mutations}

Mice were co-housed and injected $10 \mathrm{mg} / \mathrm{kg}$ body weight azoxymethane (Sigma-Aldrich) i.p. on day 1 , day 8 and day 15 . Mice were sacrificed on day 75 , when no macroscopic tumor development could be observed. Epithelial cells from the colon were isolated as described above and genomic DNA was extracted using QIAamp Fast DNA Tissue Kit (Qiagen) according to the manufacturer's instructions. Competitive Allele-Specific TaqMan (cast) PCR (Thermo Fisher) was used to detect single basepair mutations in the $C t n n b 1$ gene. AOM-induced mutations were derived from the literature 45 and compared to OMIM database to find conserved mutations and high frequency targets were chosen (CTNNB1_5676_mu, b.C122I, p.T41I; CTNNB1_5671_mu, b.G101A, p.G34E; CTNNB1_5672_mu, b.G94A p.D32N). For reference quantification of total Ctnnb1 gene expression, quantitative RT-PCR was performed as described above. TaqMan PCR was carried out according to the manufacturer's instructions (Thermo Fisher).

\section{Mouse diets}

Mice were generally fed ad libitum with standard grain-based rodent diet (R/M-H Extrudat, sniff). This diet is also referred to as control diet (CD) during the experiments with defined diets. To analyze the impact of dietary glucosinolates, mice were switched to an experimental defined diet at the age of 6 weeks and fed with this diet for 6 weeks when the analyses were performed. The defined diet (EDD-) (EF/RM low chlorophyll; sniff) is devoid of any plant-derived phytochemicals and is regularly tested to be free of chlorophyll, flavonoids and glucosinolates. The defined diet was supplemented with $2 \mathrm{~g} / \mathrm{kg}$ indole-3carbinol (EDD+) (I3C, Sigma-Aldrich). All diets contained the same amount of metabolizable energy and equivalent compositions of proteins, carbohydrates, fat, trace elements, minerals and vitamins 27.

\section{Treatment with AhR ligands}

1-methoxy-3-indolylmethyl alcohol (1-MIM-OH, synthesized as described elsewhere26) and $\mathrm{I} 3 \mathrm{C}$ were dissolved in corn oil (Sigma-Aldrich) and gavaged at a concentration of $106 \mathrm{mg} / \mathrm{kg}$ body weight. After the indicated timepoints, mice were sacrificed and small intestine and colon were processed, as described above. Caecum was removed, cleaned and snap frozen in liquid nitrogen. Tissue was later homogenized and genomic DNA was extracted using QIAamp Fast DNA Tissue Kit (Qiagen) according to the manufacturer's instructions.

\section{DNA adduct analysis}

Caecal tissue was harvested as described before and genomic DNA was extracted using QIAamp Fast DNA Tissue Kit (Qiagen) according to the manufacturer's instructions. 25 $\mu \mathrm{g}$ of isolated DNA were spiked with stable isotopically labeled adduct standards and hydrolyzed to 2'-deoxynucleosides (dN) according to our optimized protocol46. After analyte enrichment by $\mathrm{C}_{18}$ solid phase extraction, the predominant DNA adducts after 1MIM-OH exposure, namely $N^{2}$-(1-MIM)-dG and $N^{6}$-(1-MIM)-dA, were analyzed by isotope-dilution liquid chromatography tandem-mass spectrometry (LC-MS/MS) as described previously47 using an Agilent 1260 Infinity LC system coupled to an Agilent 6490 triple quadrupole-mass spectrometer (Agilent Technologies) interfaced with an 
electrospray ion source operating in the positive ion mode (ESI+). Further, in the DNA hydrolyzate prior to sample purification, we analyzed the amounts of $\mathrm{dC}$ and $5 \mathrm{mdC}$ (5methyl-2'-deoxycytidine) by isotope-dilution LC-MS/MS as recently published48. We calculated the amount of DNA that was actually used for the adduct analysis knowing that $\mathrm{dC}$ (in fact the sum of $\mathrm{dC}$ and $5 \mathrm{mdC}$ ) accounts for $21 \%$ of the total $\mathrm{dN}$ in the mouse genome.

\section{Statistical Analysis}

p-value of data sets was determined by unpaired two-tailed Student's t-test with 95\% confidence interval. Normal distribution was assumed. All statistical tests were performed with Graph Pad Prism V7 software. (*p $\leq 0.05$, **p $\leq 0.01$, and ***p $\leq 0.001$; n.s., not significant). All plots are shown as mean \pm SEM. 


\section{Extended Data}

a

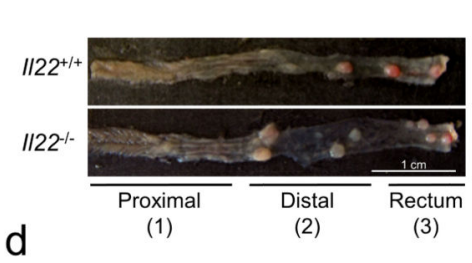

b

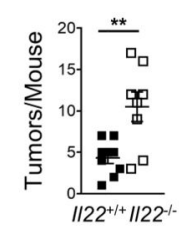

C
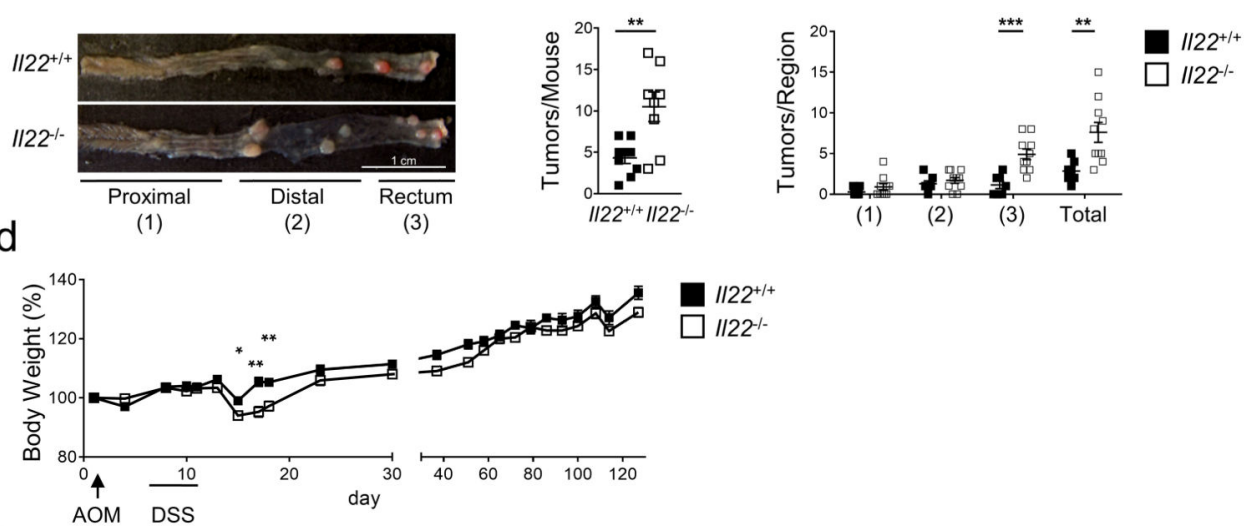

e
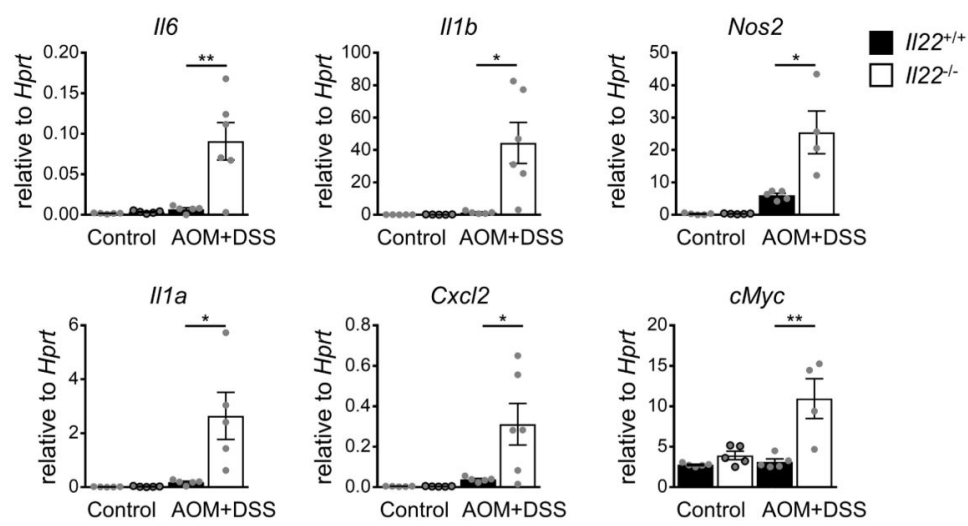

f

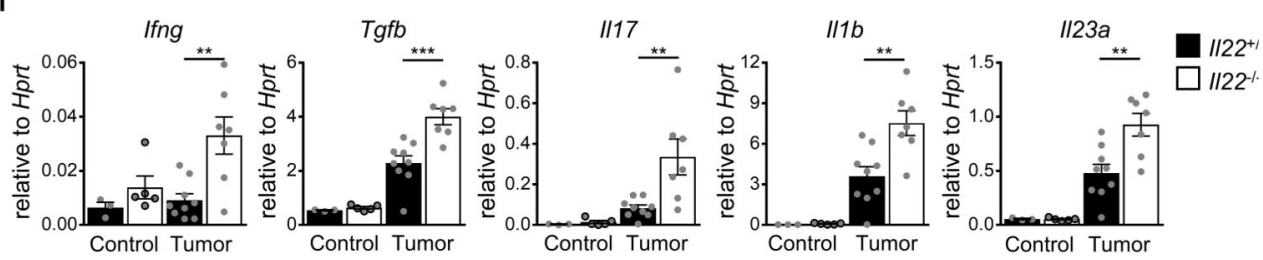

g

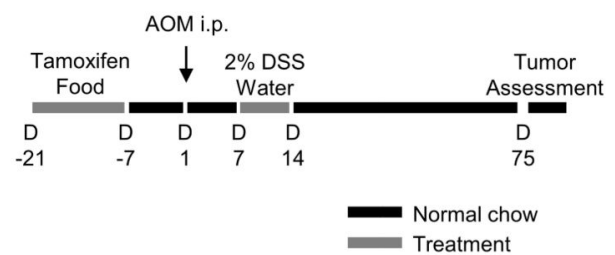

Extended Data Figure 1. Increased inflammation in $I l 22^{-/}$mice during AOM/DSS carcinogenesis (a-f) Mice were given one dose of AOM i.p. followed by one week of 2\% DSS in drinking water. (a) Tumor development in $I 122^{+/+}$and $I I 22^{/-}$mice. Scale bar=1 $\mathrm{cm}$. Tumor number (b) $\left(I I 22^{+/+} \mathrm{n}=9, I I 22^{-/} \mathrm{n}=8\right.$, mean \pm SEM; $\left.\mathrm{p}=0.022\right)$ and regional distribution of tumors (c) $\left(I I 22^{+/ t} \mathrm{n}=7, I I 22^{-/} \mathrm{n}=10\right.$, mean \pm SEM; $\mathrm{p}_{\text {Rectum }}=0.0007$, $\left.\mathrm{p}_{\text {Total }}=0.0078\right)$. (d) Body weight as percent of initial weight $\left(I I 22^{+/+} \mathrm{n}=7, I I 22^{/-} \mathrm{n}=10\right.$, mean \pm SEM $)$. (e) Expression of the 
indicated inflammatory and tumor-promoting genes $(n=4-6$, mean \pm SEM) in colonic mucosa was assessed by qRT-PCR two days after DSS treatment was stopped. (f) Expression of the indicated genes was analyzed by qRT-PCR within tumors ( $n=3-9$, mean \pm SEM).

(g) Schematic representation of the CAC treatment regimen in mice with sporadic inactivation of the II22ral gene $\left(I I 22 r a I^{\mathrm{fl} / \mathrm{fl} 1} ; \mathrm{Lgr}_{5} 5^{\mathrm{CreER} 2 /+} ; R 26 R\right.$-Confetti and II22raI ${ }^{\mathrm{fl} /+} ;$ Lgr $5^{\mathrm{CreERt} /+} ;$; 26 -Confetti).

Data are representative of two biologically independent experiments.

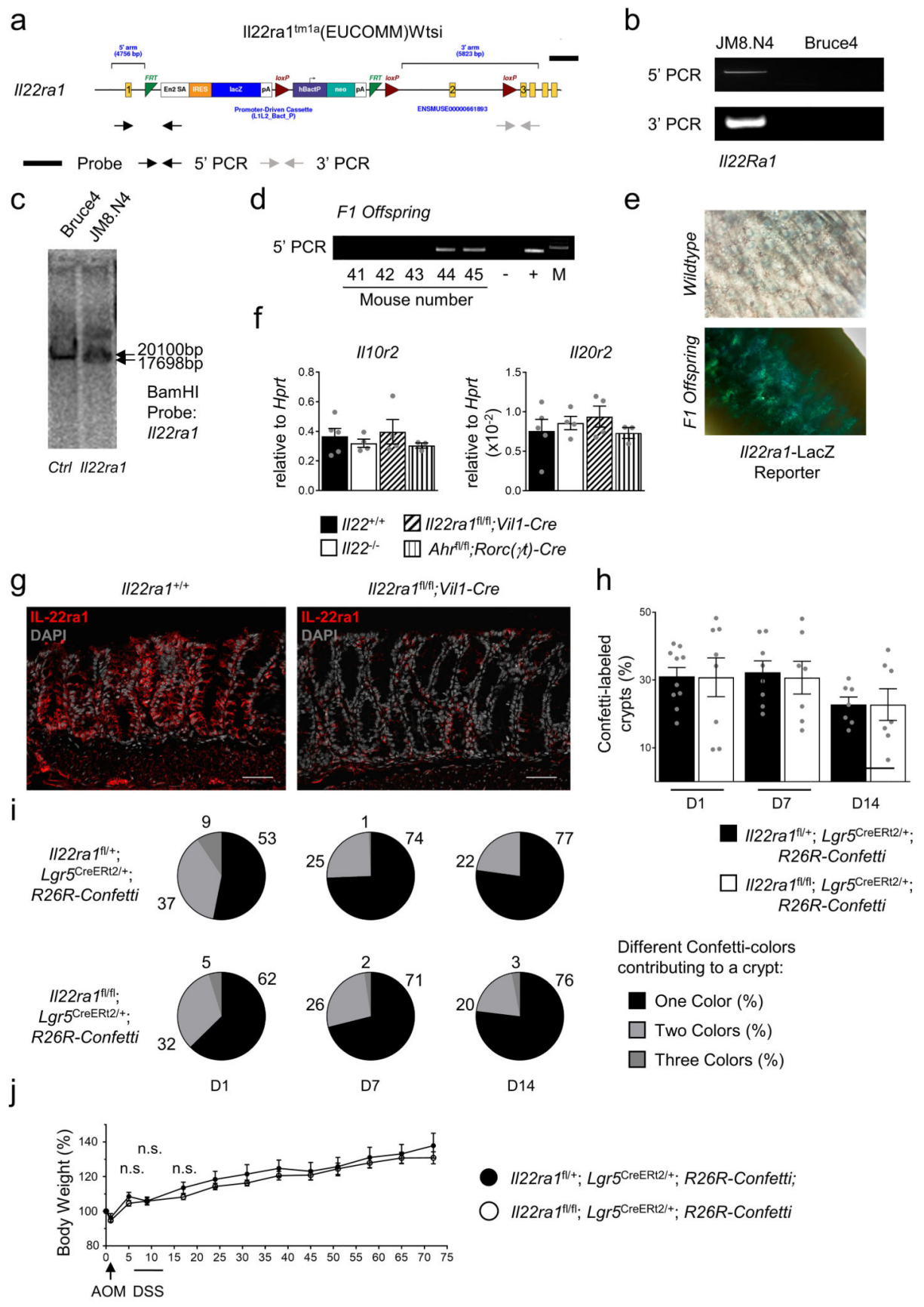

Nature. Author manuscript; available in PMC 2019 July 30. 
Extended Data Figure 2. Generation and validation of $\mathrm{Il}_{22 \mathrm{ral}} \mathrm{I}^{\mathrm{flox}}$ mice

(a) Schematic representation of the II22ra $I^{\mathrm{tm} 1 \mathrm{a}(\mathrm{EUCOMM}) \mathrm{Wtsi}}$ allele in targeted ES cells. The position of PCR primers and Southern blot probes is indicated.

(b) Verification of construct integration into JM8.N4 ES cells by genomic PCR. DNA from untargeted ES cells (Bruce4) served as a control.

(c) Southern blot after BamHI digestion confirming the correct integration of the construct, which introduced a novel BamHI recognition site into the genomic DNA.

(d) Germline transmission was assessed by genomic PCR in the F1 generation.

(e) LacZ reporter activity was assessed in F1 mice.

(f) Gene expression of the IL-22Ra1 binding partners in colonic epithelial cells of the indicated mouse strains was assessed by qRT-PCR $\left(I 122^{+/+} \mathrm{n}=5, I 122^{-1-} \mathrm{n}=4, I 122 \mathrm{ra} I^{\mathrm{fl} / \mathrm{fl}}\right.$; VillCre n=4, $A h r^{\mathrm{fl} / \mathrm{fl}}$;Rorc $(\gamma t)-C r e \mathrm{n}=3$, mean \pm SEM).

(g) Representative immunofluorescence images of IL-22Ra1 (red) in colonic epithelial cells. Scale bar $=50 \mu \mathrm{m}$.

(h-i) II22ra ${ }^{\mathrm{fl} / \mathrm{fl}} ;$ Lgr $^{\mathrm{CreERt} 2 /+} ; R 26 R$-Confetti or II22ra ${ }^{\mathrm{fl} /+} ;$ Lgr $^{\mathrm{CreERt} 2 /+} ; R 26 R-$ Confetti mice were fed with a tamoxifen-containing diet for two weeks. (h) Labeling efficiency (\%)

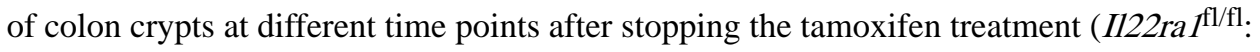
II22raI ${ }^{\mathrm{fl} /+}$; day1 $\mathrm{n}=8: 10$; day7 $\mathrm{n}=7: 8$; day14 $\mathrm{n}=7: 7$ visual fields, mean $\pm \mathrm{SEM}$ ). (i) Fraction (\%) of Confetti ${ }^{+}$crypts (mean) with one, two or three colors.

(j) The indicated mouse strains were fed with tamoxifen-containing diets and subjected to

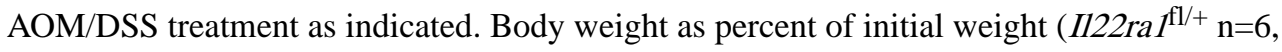
II22ra $I^{\mathrm{fl} / \mathrm{fl}} \mathrm{n}=10$, mean $\left.\pm \mathrm{SEM}\right)$.

Data are representative of two (f-j) biologically independent experiments. 
a

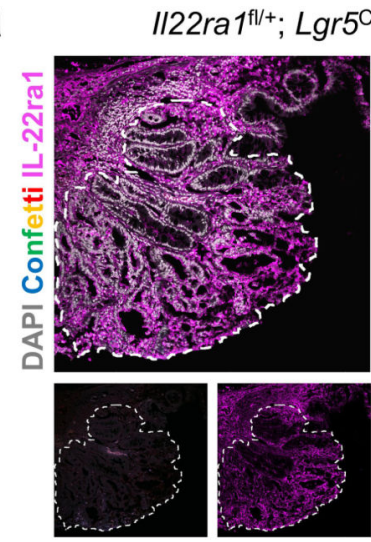

Confetti

IL-22ra1

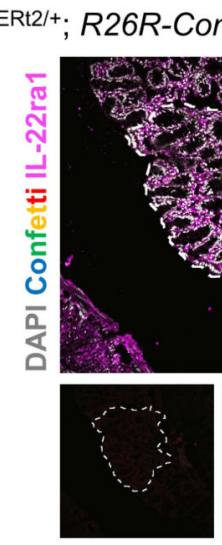

Confetti

b

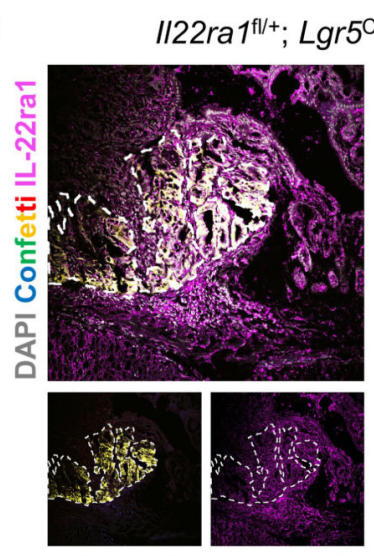

Confetti

IL-22ra1

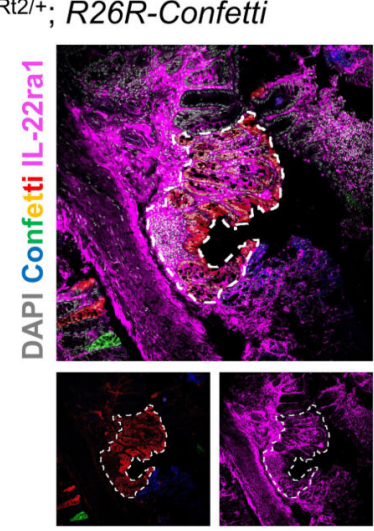

Confetti

IL-22ra1

d
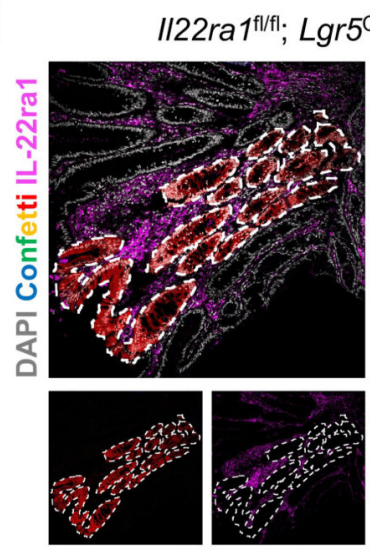

Confetti IL-22ra1

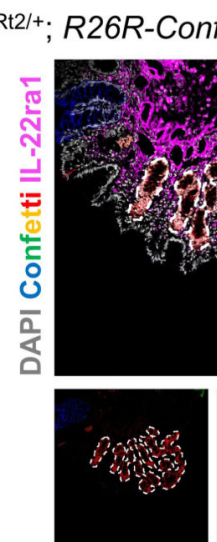

Confetti tti

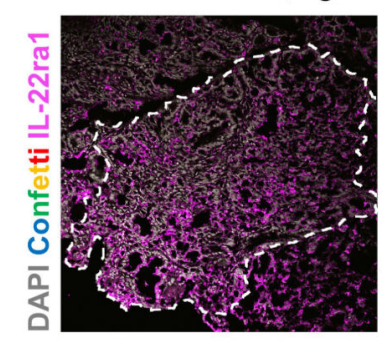

$a_{1 . \ldots \ldots}$

Confetti

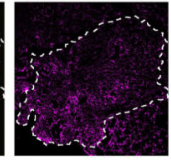

IL-22ra1

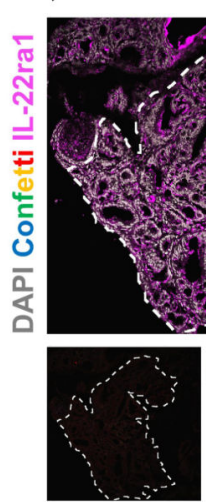

Confetti
IL-22ra1

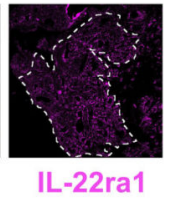

e

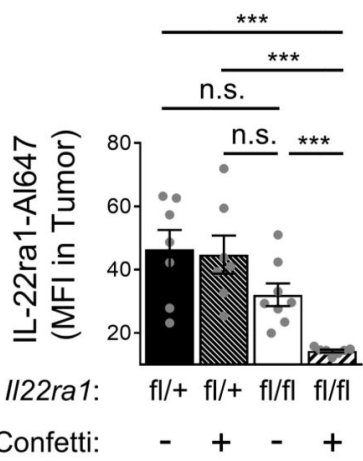

Extended Data Figure 3. IL-22Ra1 expression in tumors from $I l 22 r a I^{\mathrm{fl} / \mathrm{fl}} ; \mathrm{Lgr}^{\mathrm{CreERt} /++} ; R 26 R$ Confetti mice

(a-d) Representative immunofluorescence images for IL-22Ra1 expression (violet) by Confetti-negative (a,c) and Confetti-positive (b,d) colon tumors from II22raI ${ }^{\mathrm{fl} /+} ;$ Lgr ${ }^{\mathrm{CreERt} 2 /+} ; R 26 R$-Confetti $(\mathbf{a , b})$ and II22raI ${ }^{\mathrm{fl} / \mathrm{fl}} ; \operatorname{Lgr}^{\mathrm{CreERt} 2 /+} ; R 26 R-$ Confetti (c,d) mice. 
(e) Mean Fluorescence Intensity (MFI) of IL-22Ra1 fluorescende across tumor area of the indicated mouse strains with and without prior Cre-activation ( $\mathrm{n}=7$; except II22raf fl/fl

Confetti-negative $n=8$, mean \pm SEM).
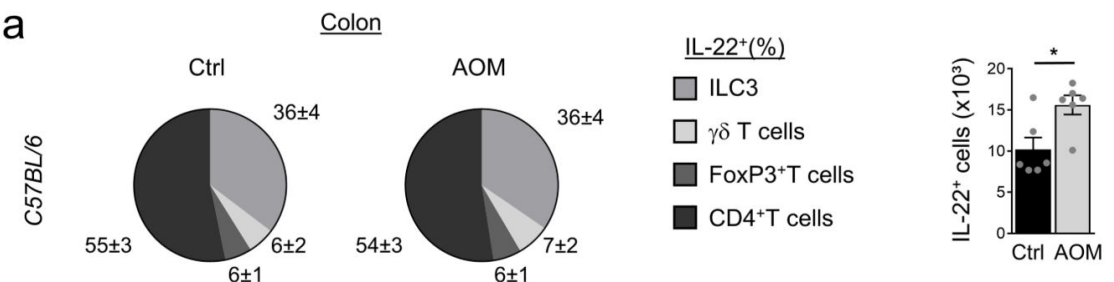

b
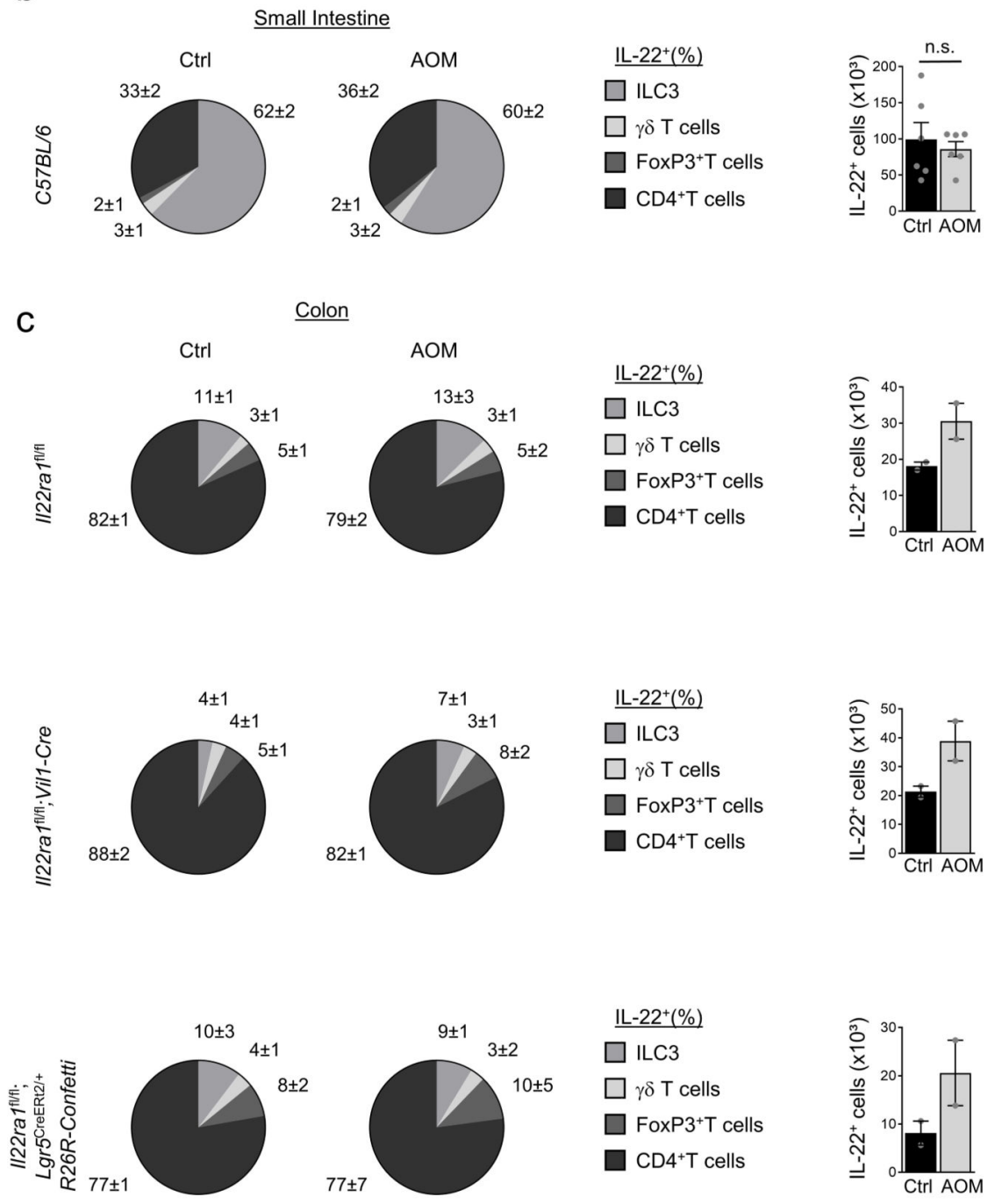

Extended Data Figure 4. Identification of IL-22-producing lymphocytes

(a-c) Mice of the indicated genotypes or strains were injected with AOM or PBS (Ctrl). 24h later, IL-22+ cells among the indicated lymphocyte subsets and absolute numbers of IL-22+ 
cells were determined. (a) Colon C57BL/6 mice ( $\mathrm{n}=6$, mean \pm SEM, $\mathrm{p}=0.0154)$, (b) small intestine C57BL/6 ( $\mathrm{n}=6$, mean \pm SEM). (c) Colon $(\mathrm{n}=2$, mean \pm SEM).

Data are representative of two (a-c) biologically independent experiments.

a
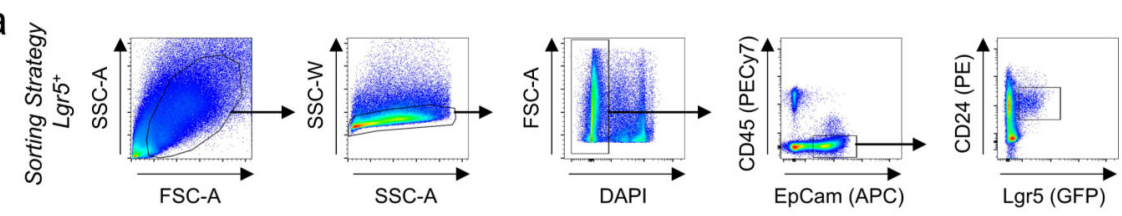

b

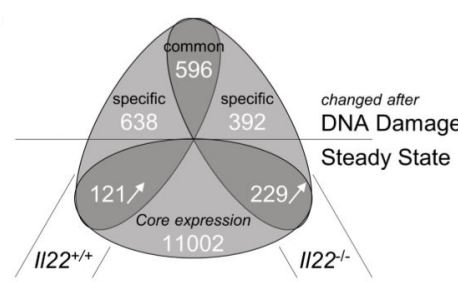

C GO DNA Double Strand_Break_Processing

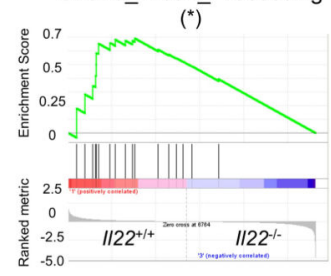

d
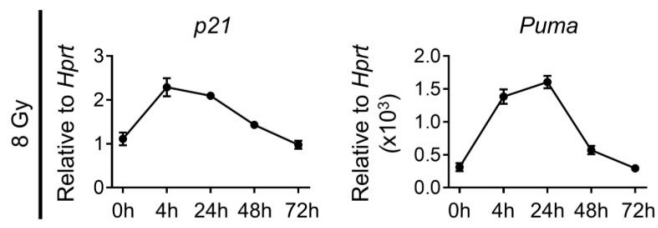

e

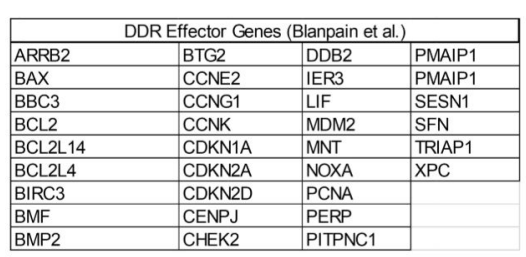

f
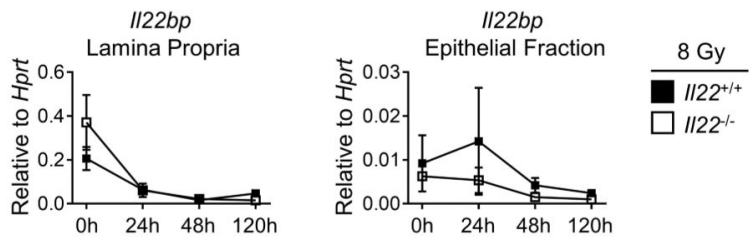

g

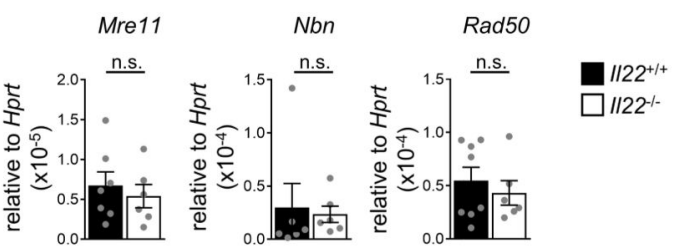

$\mathrm{h}$
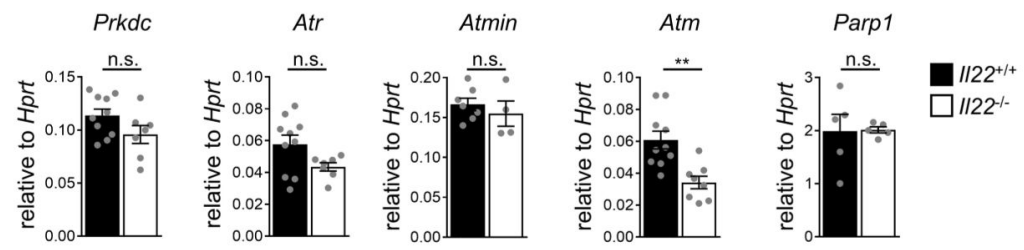

Extended Data Figure 5. Initiation of the DDR is impaired in $\mathrm{Il22}^{-/-}$mice

(a-c) $I I 22^{+/+} ; L g r 5^{\text {Egfp }}$ and $I I 22^{-/} ; L g r 5^{\text {Egfp }}$ mice (n=3 each) were irradiated with 8 Gy ("DNA damage") or left untreated ("steady-state"). Lgr5 (GFP) ${ }^{+}$colon epithelial stem cells were highly purified and gene expression was analyzed by RNA-seq. (a) Sorting strategy for 
colonic $\mathrm{Lgr}^{+}$stem cells. Stem cells were highly purified (>98\%) for RNA-seq analysis. (b) Modified Venn diagram. All expressed genes with FC $>2$ were extracted and plotted. Bottom half represents genes differentially expressed between $I I 22^{+/+}$and $I I 22^{/-}$mice at the steadystate. "Core expression" contains all genes with detectable transcripts that were not differentially expressed. Upper half depicts genes differentially expressed 24h after irradiation in comparison to untreated mice. Of these, 596 genes differed in both genotypes, whereas 638 genes were only regulated in stem cells of $I 122^{+/+}$mice and 392 in $I 122^{/-}$mice. (c) Gene set enrichment analysis (GSEA) was performed on all expressed transcripts

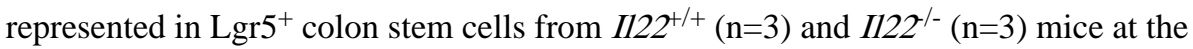
steady-state. Nominal p-value (Kolmogorov-Smirnov) was calculated for GO_DNA_Double_Strand_Break_Processing $(\mathrm{p}=0.01)$.

(d) Mice were were irradiated with 8 Gy. Expression ( $n=3$, mean \pm SEM) of DDR effector genes $p 21$ and Puma in colonic epithelial cells was determined by qRT-PCR at the indicated timepoints after irradiation.

(e) List of genes included in the GSEA gene set "DDR_Effector_Genes" (Fig. $2 b) 4$.

(f) Mice were irradiated with 8 Gy. II22bp (II22ra2) gene expression in lamina propria cells or colon epithelial cells was determined by qRT-PCR at the indicated timepoints $(n=3$, mean \pm SEM).

(g,h) Expression of the indicated genes in colon epithelial cells was determined by qRT-PCR at steady-state. (g) MRN-complex genes $\left(I I 22^{+/+} \mathrm{n}=7, I I 22^{/-} \mathrm{n}=6\right.$, mean \pm SEM) (h) DDR transducer genes $\left(I I 22^{+/+} \mathrm{n}=10\right.$, except Atmin $\mathrm{n}=7$ and Parp1 $\mathrm{n}=5, I I 22^{--} \mathrm{n}=7$, except Atmin $\mathrm{n}=4$ and $\operatorname{Parp} 1 \mathrm{n}=5$, mean \pm SEM). 
a

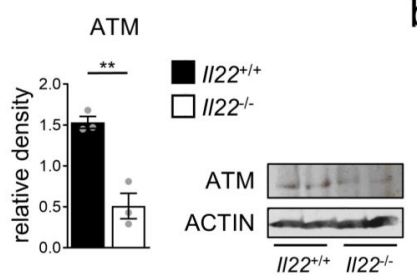

b

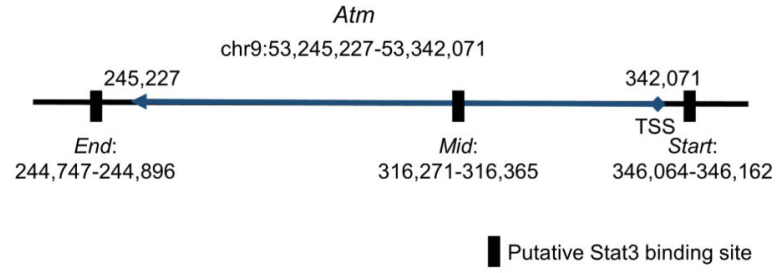

C

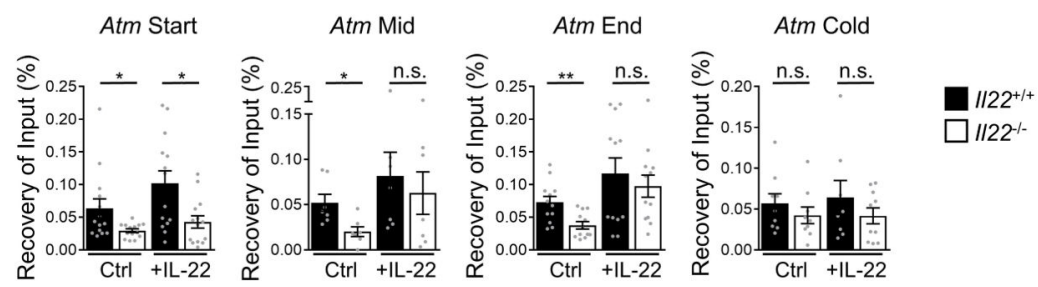

d

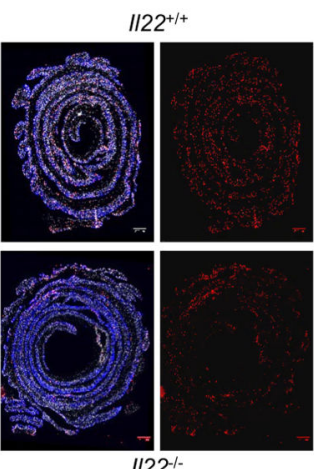

$1122^{-/-}$

g

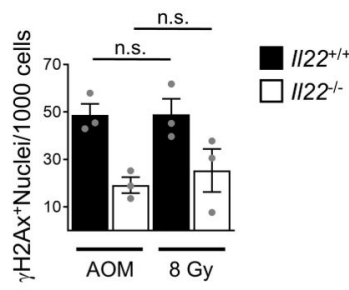

II22raffl/fl; Vil1-Cre

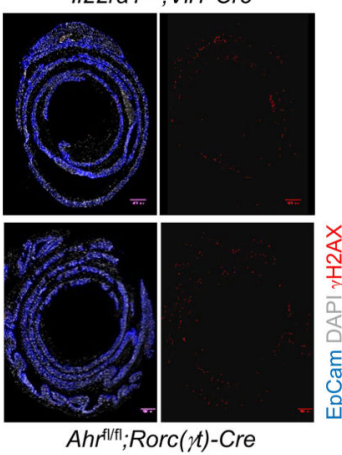

h

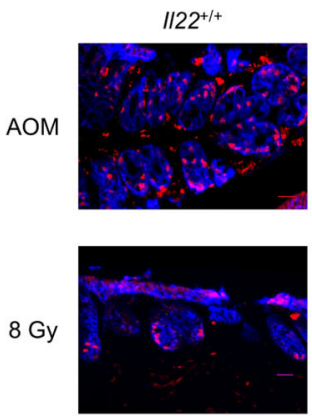

e

f

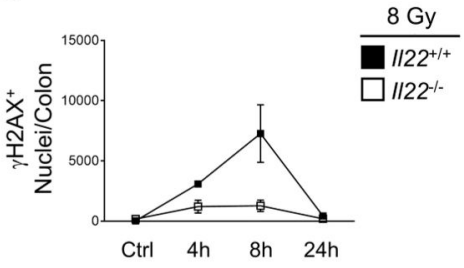

$\mathrm{H} 2 \mathrm{AX}$

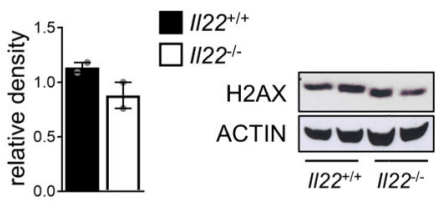

$1122^{-1-}$

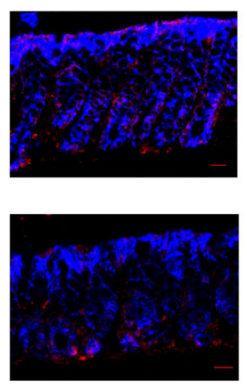

EpCam $\gamma \mathrm{H} 2 \mathrm{Ax}$

Extended Data Figure 6. IL-22 regulates ATM expression and formation of $\gamma \mathrm{H} 2 \mathrm{AX}$

(a) Immunoblot analysis of ATM from colon epithelial cells. Densitometric quantification of signal intensity normalized to loading controls ( $\mathrm{n}=3$, mean \pm SEM; $\mathrm{p}=0.004$ ).

(b) Schematic representation of STAT3 binding sites in the Atm gene locus.

(c) STAT3 ChIP was performed to determine specific pulldown at the transcription factor binding sites (Start, Mid, End) in the promoter regions of the Atm gene and at a control site within the Stat3 gene (Cold). Genomic DNA from colon epithelial cells of $I 122^{+/+}$and $I 122^{-/-}$ mice before and after in vivo stimulation with recombinant IL-22. Results represent specific 
pull down relative to a DNA input sample (Start $n=14$, Mid $n=7$, End $n=12$, Cold $n=8$, mean \pm SEM).

(d,e) Mice of the indicated genotypes were irradiated with 8 Gy. (d) Immunofluorescence analysis of $\gamma \mathrm{H} 2 \mathrm{AX}$ (red) and of EpCam (blue) of the entire colon was performed $8 \mathrm{~h}$ after irradiation. Scale bar $=500 \mu \mathrm{m}$. (e) Quantification (Ctrl, $4 \mathrm{~h}$ and $24 \mathrm{~h} \mathrm{n}=2,8 \mathrm{~h} \mathrm{n}=3$, mean $\pm \mathrm{SEM}$ ) of $\gamma \mathrm{H} 2 \mathrm{AX}^{+}$nuclei per colon before and at the indicated timepoints after irradiation.

(f) Immunoblot analysis of $\mathrm{H} 2 \mathrm{AX}$ protein and densitometric quantification of signal intensity (normalized to loading controls) in primary colon epithelial cells of $I 122^{+/+}$and II $22^{-}$mice (mean $\pm \mathrm{SEM}, \mathrm{n}=2$ ).

(g,h) Mice were irradiated with 8 Gy or injected with AOM i.p. Immunofluorescence analysis of colon sections was performed $8 \mathrm{~h}$ after damage. Quantification $(\mathbf{g})(\mathrm{n}=3$, mean $\pm \mathrm{SEM}$ ) of $\gamma \mathrm{H} 2 \mathrm{AX}^{+} \mathrm{EpCam}^{+}$cells and representative immunofluorescence images (h) after $\gamma \mathrm{H} 2 \mathrm{AX}$ (red) and EpCam (blue) staining. Scale bar $=25 \mu \mathrm{m}$. 
a
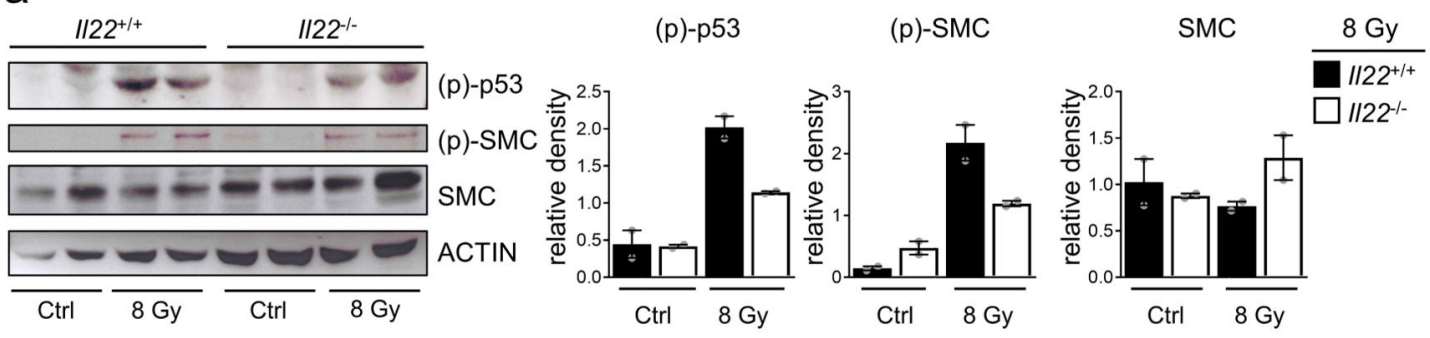

b
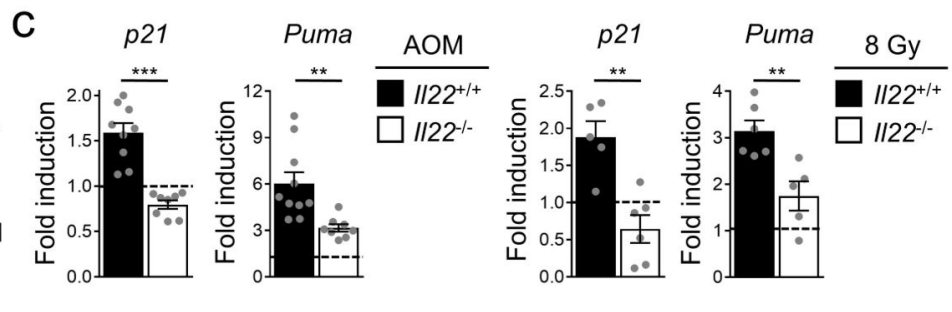

d

e
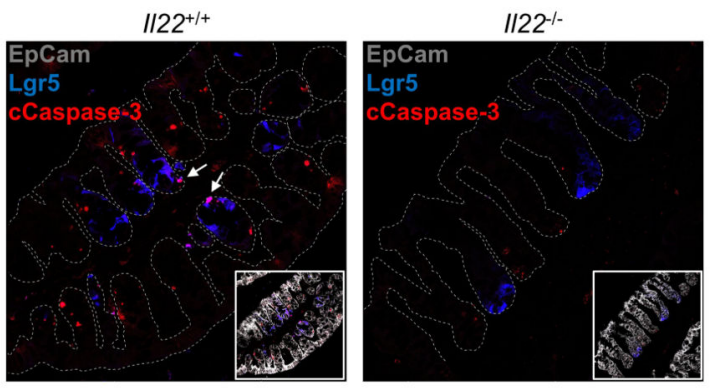

$f$

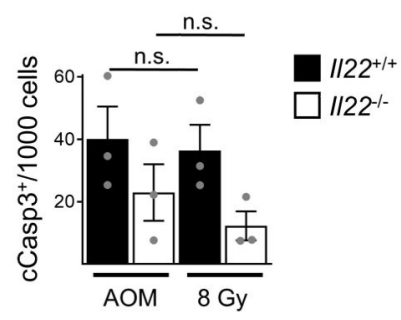

g

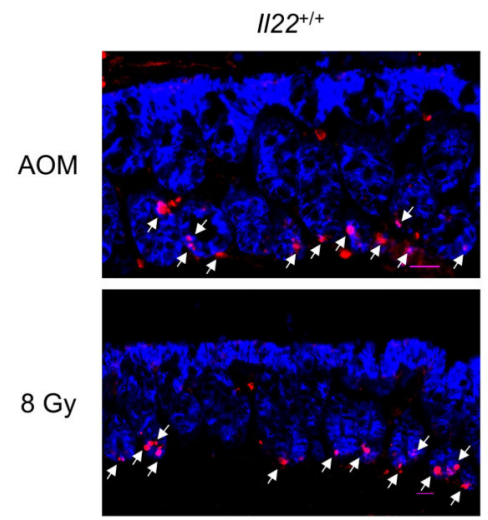

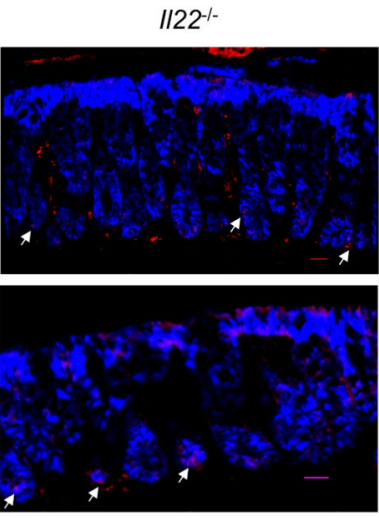

EpCam cCaspase-3

Extended Data Figure 7. Impairment of p53 activation and DDR effector genes in $1122^{-/-}$mice (a-g) Mice were irradiated with 8 Gy or injected with AOM. (a,b) Immunoblot analysis of the indicated proteins from primary colon epithelial cells $24 \mathrm{~h}$ after irradiation. Densitometric quantification of signal intensity (mean \pm SEM, $n=2$ ). p-p53 and Actin, p-SMC and SMC, PUMA and Actin, and p21 immunoblots were derived from one gel each. Normalization was done to loading (p-p53, PUMA) or sample processing (p-SMC, SMC, p21) controls. (c,d) Fold induction of $p 21$ and Puma gene expression in colon epithelial cells $24 \mathrm{~h}$ after irradiation or AOM treatment was determined by qRT-PCR (AOM n=10, 8 Gy n=5, Stat $3^{\mathrm{fl} / \mathrm{fl}}$ 
$\mathrm{n}=4$, Stat $^{\mathrm{fl} / \mathrm{fl} l} ;$ Vil1-Cre $\mathrm{n}=5$, mean $\pm \mathrm{SEM}$ ). (e) Apoptosis (red: cleaved (c)Caspase-3) in $\mathrm{Lgr}^{+}$(blue) colon stem cells (arrows). Representative immunofluorescence images $8 \mathrm{~h}$ after irradiation. (f,g) Quantification of cleaved Caspase- $3^{+} \mathrm{EpCam}^{+}$colonic epithelial cells $8 \mathrm{~h}$ after treatment with AOM or 8 Gy $(\mathbf{f})(n=3$, mean \pm SEM $)$ and representative immunofluorescence images (g) (cleaved Caspase-3, red and EpCam, blue). Scale bar $=25 \mu \mathrm{m}$ Data are representative of two $(\mathbf{d}-\mathbf{g})$ or three (a-c) biologically independent experiments

a
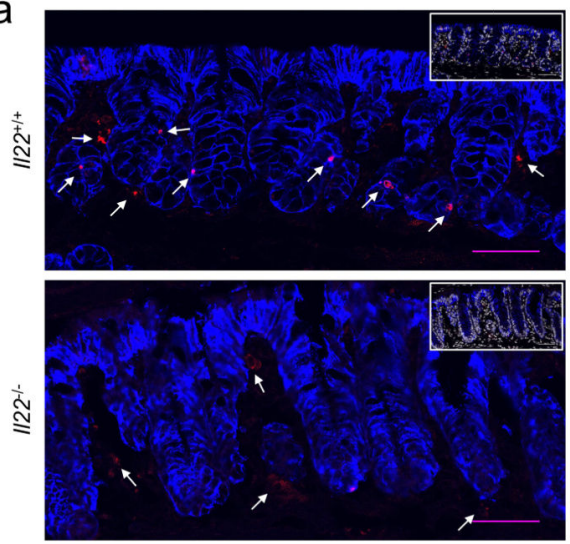

b

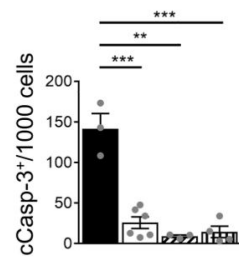

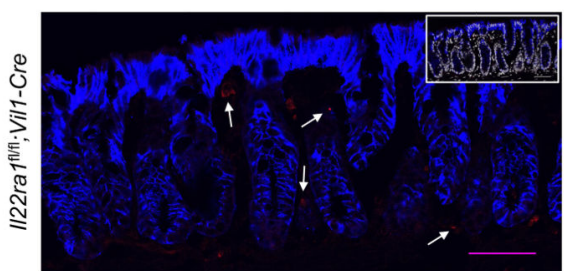

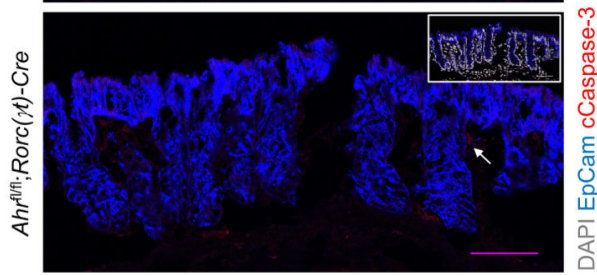

C

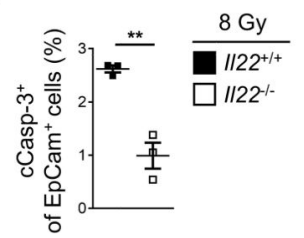

d
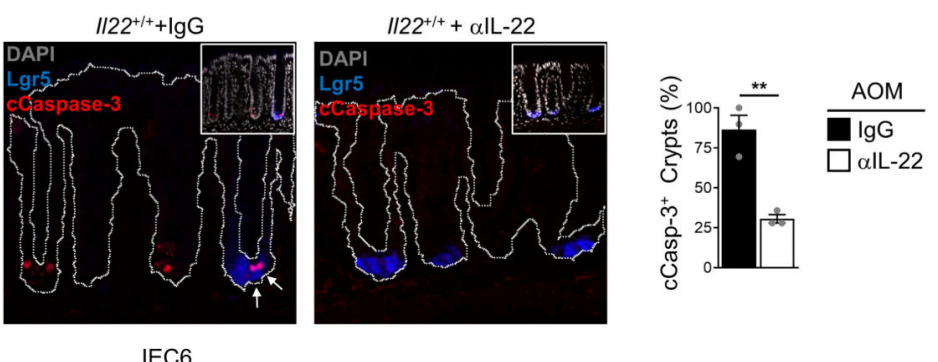

e

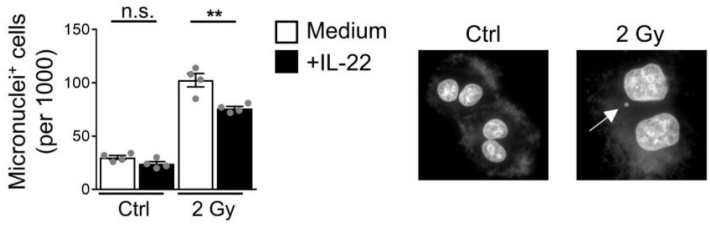

f

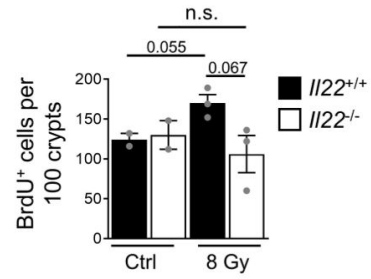

Extended Data Figure 8. Impairment of DDR-triggered apoptosis in $I l 22^{-/-}$mice

Nature. Author manuscript; available in PMC 2019 July 30. 
(a-c) Mice of the indicated genotypes were irradiated with $8 \mathrm{~Gy}$ and analyzed 8h later. (a) Immunofluorescence for cleaved Caspase-3 (red) and EpCam (blue). Scale bar=50 $\mu \mathrm{m}$. Quantification of cCasp- $3^{+}$cells by histology (b) $\left(I I 22^{+/+} \mathrm{n}=3, I 122^{/-} \mathrm{n}=6\right.$, II22ra $\mathrm{fl}^{\mathrm{fl} / \mathrm{fl}}$; Vil1$\operatorname{Cre} \mathrm{n}=3, A h r^{\mathrm{fl} / \mathrm{fl}} ; \operatorname{Rorc}(\gamma t)-\operatorname{Cre} \mathrm{n}=4$, mean $\left.\pm \mathrm{SEM}\right)$ or by flow cytometry $(\mathbf{c})(\mathrm{n}=3$, mean \pm SEM, $\mathrm{p}=0.003$ ).

(d) IL-22 neutralizing antibody or control IgG was injected i.p. 36h, $12 \mathrm{~h}$ before and $12 \mathrm{~h}$ after AOM application. Representative immunofluorescence images of the colon $24 \mathrm{~h}$ after AOM treatment stained for Lgr5 (blue) and cleaved Caspase-3 (red; arrows indicate apoptotic stem cells). Quantification of cCasp- $3^{+}$crypts ( $n=3$, mean \pm SEM, $p=0.0039$ ).

(e) IL-22-responsive IEC6 cells were cultured with or without recombinant IL-22. Cells were irradiated with 2 Gy or left untreated and cultured in the presence of cytochalasin B. DNA was visualized with DAPI $48 \mathrm{~h}$ after irradiation. Number of cells containing one or more micronuclei $(\mathrm{n}=4$, mean \pm SEM). Representative images of untreated $(\mathrm{Ctrl})$ or irradiated (2 Gy) IEC6 cells. Arrow illustrates a micronucleus.

(f) Mice of the indicated genotypes were irradiated with $8 \mathrm{~Gy}$. Quantification of $\mathrm{BrdU}^{+}$cells in colonic crypts. $(n=3$, mean \pm SEM)

Data are representative of two biologically independent experiments 
a

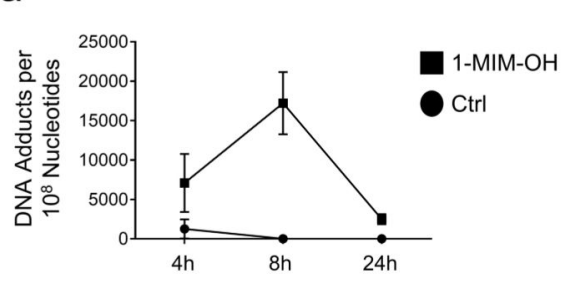

b

$\underline{\text { Short term application of AhR ligands }}$

Gavage Isolation of Epithelium \& 1-MIM-OH/I3C Lymphocytes

Feeding of experimental diets

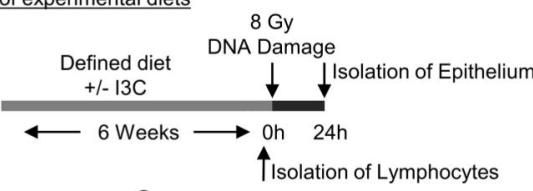

C

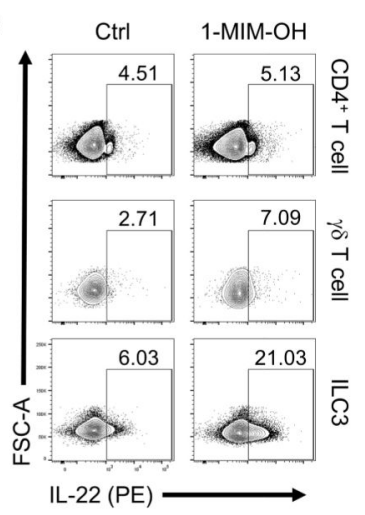

d

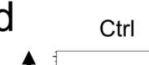

I3C

e
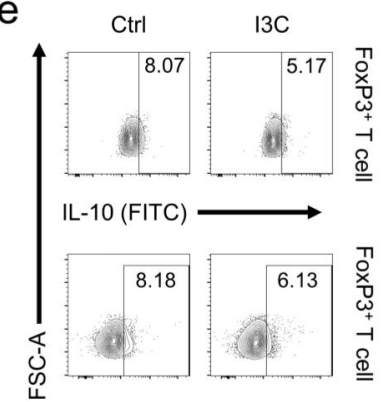

IL-22 (PE)

FoxP3 ${ }^{+} \mathrm{T}$ cell $\mathrm{FoxP}^{+} \mathrm{T}$ cell

IL-22 (PE)
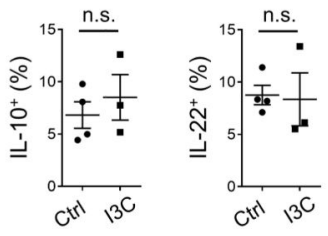

f

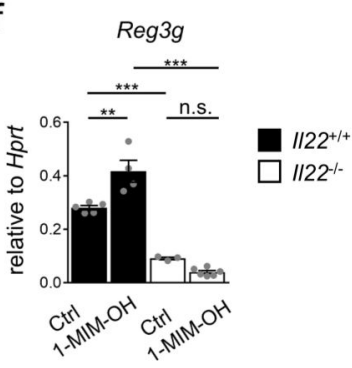

h

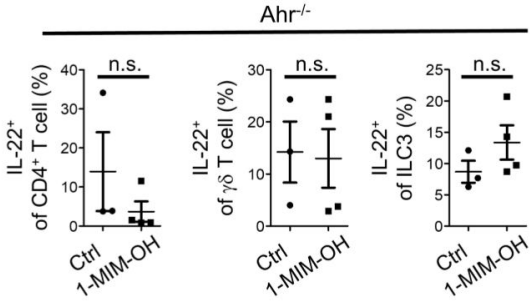

g

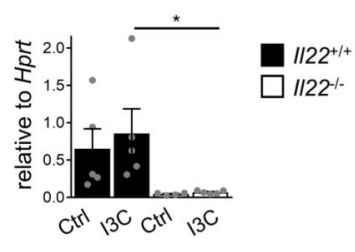

1-MIM-OH

$\mathrm{Ctrl}$

Extended Data Figure 9. Dietary AhR-ligands promote IL-22 production

(a) Wildtype mice were given 1-MIM-OH or carrier control (Ctrl) by gavage. Quantification of DNA adducts at the indicated time points ( $\mathrm{Ctrl} 4 \mathrm{~h} n=2, \mathrm{Ctrl} 8 \mathrm{~h} \mathrm{n}=4, \mathrm{Ctrl} 24 \mathrm{~h} \mathrm{n}=2,1$ MIM-OH 4h n=4, 1-MIM-OH 8h n=8, 1-MIM-OH 24h n=6, mean \pm SEM).

(b) Schematic representation of the different treatment regimens.

(c-g) Mice of the indicated genotypes were exposed to 1-MIM-OH (c,f) or I3C (d,e,g) by gavage and analyzed $8 \mathrm{~h}$ later. (c,d) Representative flow cytometry analysis of IL-22 production by the indicated lymphocyte populations after gavage with 1-MIM-OH or I3C. 
$\mathrm{CD}^{+} \mathrm{T}$ cells were defined as $\mathrm{CD} 45^{+}$lineage marker $(\mathrm{Lin})^{+} \mathrm{CD} 4^{+}$cells, ILC3 as $\mathrm{CD} 45^{+}$ $\mathrm{Lin}^{-} \mathrm{ROR} \gamma \mathrm{t}^{+}$cells, and $\gamma \delta \mathrm{T}$ cells as $\mathrm{CD}^{+} 5^{+} \mathrm{Lin}^{+} \gamma \delta \mathrm{TCR}^{+}$cells. Numbers indicate percent of cells in gate. (e) Representative flow cytometry analysis and quantification of IL-22 and IL-10 production by $\mathrm{Lin}^{+} \mathrm{CD}^{+}{ }^{+} \mathrm{FoxP}^{+} \mathrm{T}$ regulatory cells $8 \mathrm{~h}$ after gavage with $\mathrm{I} 3 \mathrm{C}$ (Ctrl $\mathrm{n}=4, \mathrm{I} 3 \mathrm{C} \mathrm{n}=4$, mean $\pm \mathrm{SEM}$ ). (f,g) Expression of the IL-22 response gene Reg3g in primary colon epithelial cells was determined by qRT-PCR $8 \mathrm{~h}$ after gavage with 1-MIM-OH (Ctrl:1MIM-OH, II22 ${ }^{+/+} \mathrm{n}=5: 4, I I 22^{/-} \mathrm{n}=3: 6$, mean $\left.\pm \mathrm{SEM}\right)$ or I3C ( $\mathrm{n}=5$, mean $\pm \mathrm{SEM}$ ).

(h) Percentage of IL-22+ cells among the indicated lymphocyte subsets $8 \mathrm{~h}$ after 1-MIM-OH treatment of $A h r^{-/}$mice ( $\mathrm{Ctrl} \mathrm{n}=3,1-\mathrm{MIM}-\mathrm{OH} \mathrm{n}=4$, mean $\pm \mathrm{SEM}$ ).

(i) Numbers of IL-22+ ILC3 at different time points after 1-MIM-OH gavage (Ctrl n=2, 1MIM-OH n=4, 1-MIM-OH 24h n=6, mean \pm SEM).

Data are representative of two biologically independent experiments. 
a

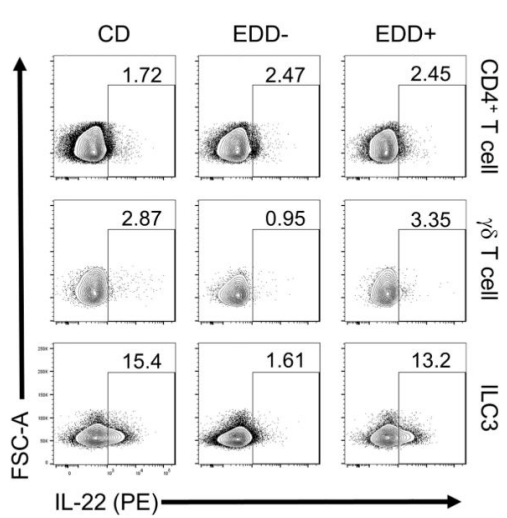

C

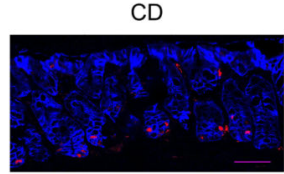

d

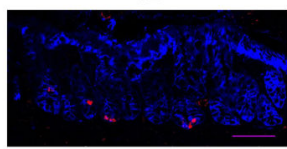

e b

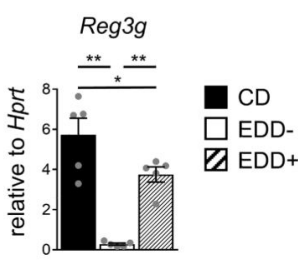

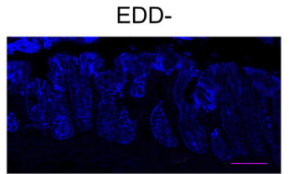

EDD-

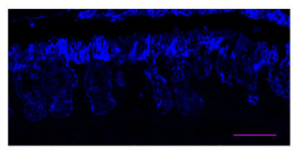

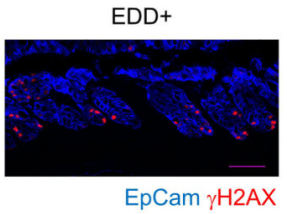

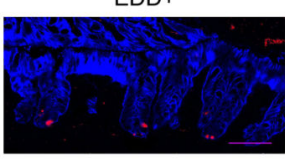

EpCam cCaspase-3

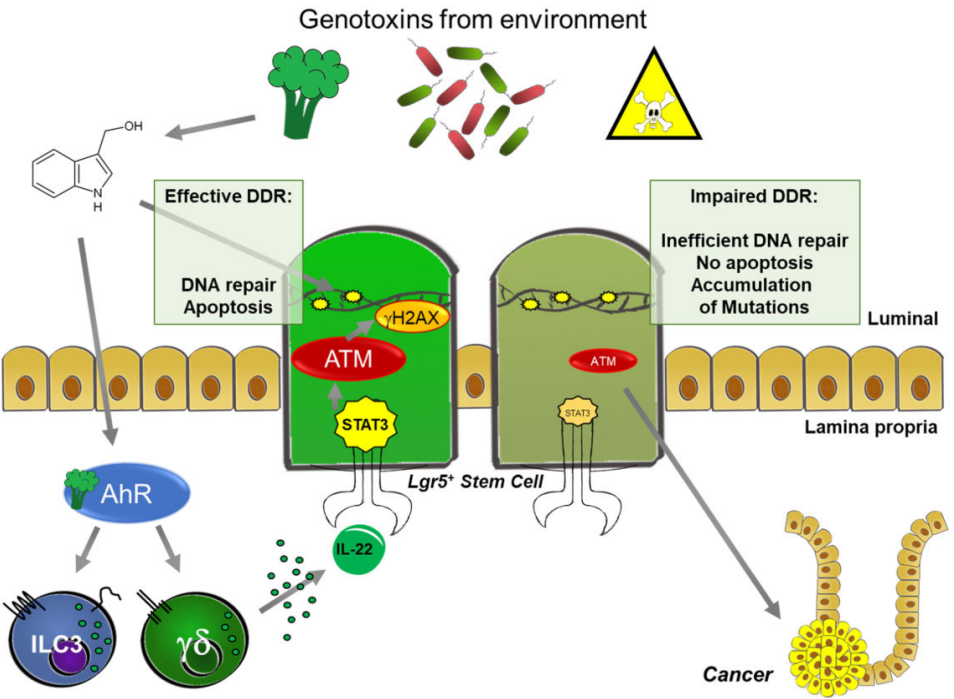

Extended Data Figure 10. Diet-derived AhR-ligands control IL-22 production (a-d) Mice were fed for 6 weeks with either normal, grain-based chow (CD), a phytochemical-free, experimental defined diet (EDD-) or EDD supplemented with the AhRligand I3C (EDD+). (a) Representative flow cytometry analysis of IL-22 production by the indicated lymphocyte populations. Numbers indicate percent of cells in gate. (b) Expression of the IL-22 responsive gene $R e g 3 g$ in primary colon epithelial cells was determined by qRT-PCR ( $\mathrm{n}=5$, mean \pm SEM). (c,d) Representative colon immunofluorescence images $8 \mathrm{~h}$ 
after irradiation and stained for $\gamma \mathrm{H} 2 \mathrm{AX}$ (red) (c) or cCasp- $3^{+}$(red) (d) and EpCam (blue).

Scale bar $=50 \mu \mathrm{m}$.

Data are representative of three biologically independent experiments.

(e) Model of IL-22-mediated protection of epithelial stem cells against genotoxic stress.

Epithelial stem cells at the intestinal barrier are continuously exposed to a variety of insults.

Among them are threats to genomic integrity represented by genotoxins, contained in diets

or produced by bacteria. Genome integrity in stem cells requires a functioning DNA damage response pathway to limit damage to the genetic code in order to prevent malignant transformation. Our data implicate a homeostatic regulatory loop that assesses the degree of "genotoxic danger" by AhR-mediated sensing of nutrient-derived genotoxins that serve as AhR ligands. AhR signaling in ILC 3 and $\gamma \delta$ T cells controls IL-22 production. IL-22 signaling in intestinal epithelial stem cells in turn controls components of the DDR. In particular ATM, a PI3-kinase-like molecule and an important upstream transducer of the DDR, was tuned-up by IL-22 signaling in stem cells. Following genotoxic stress, ATM controls downstream events of the DDR such as p53 activation and expression of the DDR effector molecules p21 and PUMA that control DNA repair and apoptosis, respectively. Disturbances of this pathway in mice genetically lacking IL-22, the IL-22 receptor or the AhR led to an impaired DDR to various forms of genotoxic stress. Consequently, intestinal epithelial stem cells from mice with impairment of IL-22 signaling or production accumulated cancer-promoting mutations and showed accelerated development of cancer.

\section{Supplementary Material}

Refer to Web version on PubMed Central for supplementary material.

\section{Acknowledgements}

We thank M.Di Virgilio, B.Epe, T.Nikolova, J.Ommer and the members of the Diefenbach laboratory for valuable discussions, and K.Oberle for excellent technical assistance. We are thankful to the IMB Flow Cytometry Core Facility (J.Hartwig, I.Schäfer and S.Möckel), the IMB Microscopy Core Facility (S.Ritz and J.Schwirz), the Deep Sequencing Facility at the MPI Immunobiology \& Epigenetics Freiburg and EUCOMM for providing targeted ES cells. The work was supported by the European Research Council (ERC StG \#311377 to A.D.), the European Union's Horizon 2020 programme (Marie Skłodowska-Curie Grant Agreement No. 744257 to J.Z.), Deutsche Forschungsgemeinschaft (TR-SFB156/A02, TR-SFB241/A01, SPP1937-DI764/9 to A.D. and KL2963/1-1 to C.S.N.K.), Einstein Foundation Berlin (Einstein Professorship to A.D.), the German Rheumatism Research Centre (to A.D. and A.T.) and the Max-Planck Society (IMPRS-MCB, MPI Freiburg to K.G., M.K-B. and P.H.).

\section{References}

1. Hanahan D, Weinberg RA. Hallmarks of cancer: the next generation. Cell. 2011; 144:646-674. DOI: 10.1016/j.cell.2011.02.013 [PubMed: 21376230]

2. Wu S, Powers S, Zhu W, Hannun YA. Substantial contribution of extrinsic risk factors to cancer development. Nature. 2016; 529:43-47. DOI: 10.1038/nature16166 [PubMed: 26675728]

3. Blokzijl F, et al. Tissue-specific mutation accumulation in human adult stem cells during life. Nature. 2016; 538:260-264. DOI: 10.1038/nature19768 [PubMed: 27698416]

4. Blanpain C, Mohrin M, Sotiropoulou PA, Passegue E. DNA-damage response in tissue-specific and cancer stem cells. Cell Stem Cell. 2011; 8:16-29. DOI: 10.1016/j.stem.2010.12.012 [PubMed: 21211780]

5. Halazonetis TD, Gorgoulis VG, Bartek J. An oncogene-induced DNA damage model for cancer development. Science. 2008; 319:1352-1355. DOI: 10.1126/science.1140735 [PubMed: 18323444] 
6. Bjeldanes LF, Kim JY, Grose KR, Bartholomew JC, Bradfield CA. Aromatic hydrocarbon responsiveness-receptor agonists generated from indole-3-carbinol in vitro and in vivo: comparisons with 2,3,7,8-tetrachlorodibenzo-p-dioxin. Proc Natl Acad Sci USA. 1991; 88:9543-9547. [PubMed: $1658785]$

7. Fu D, Calvo JA, Samson LD. Balancing repair and tolerance of DNA damage caused by alkylating agents. Nat Rev Cancer. 2012; 12:104-120. DOI: 10.1038/nrc3185 [PubMed: 22237395]

8. Greten FR, et al. IKKbeta links inflammation and tumorigenesis in a mouse model of colitisassociated cancer. Cell. 2004; 118:285-296. DOI: 10.1016/j.cell.2004.07.013 [PubMed: 15294155]

9. Martincorena I, et al. Universal Patterns of Selection in Cancer and Somatic Tissues. Cell. 2017; 171:1029-1041 e1021. DOI: 10.1016/j.cell.2017.09.042 [PubMed: 29056346]

10. Bailey MH, et al. Comprehensive Characterization of Cancer Driver Genes and Mutations. Cell. 2018; 173:371-385 e318. DOI: 10.1016/j.cell.2018.02.060 [PubMed: 29625053]

11. Huber S, et al. IL-22BP is regulated by the inflammasome and modulates tumorigenesis in the intestine. Nature. 2012; 491:259-263. DOI: 10.1038/nature11535 [PubMed: 23075849]

12. Lindemans CA, et al. Interleukin-22 promotes intestinal-stem-cell-mediated epithelial regeneration. Nature. 2015; doi: 10.1038/nature16460

13. Zenewicz LA, et al. IL-22 deficiency alters colonic microbiota to be transmissible and colitogenic. J Immunol. 2013; 190:5306-5312. DOI: 10.4049/jimmunol.1300016 [PubMed: 23585682]

14. Barker N, et al. Crypt stem cells as the cells-of-origin of intestinal cancer. Nature. 2009; 457:608611. DOI: 10.1038/nature07602 [PubMed: 19092804]

15. Barker N, et al. Identification of stem cells in small intestine and colon by marker gene Lgr5. Nature. 2007; 449:1003-1007. [PubMed: 17934449]

16. Snippert HJ, et al. Intestinal crypt homeostasis results from neutral competition between symmetrically dividing Lgr5 stem cells. Cell. 2010; 143:134-144. [PubMed: 20887898]

17. Sanos SL, et al. RORgammat and commensal microflora are required for the differentiation of mucosal interleukin 22-producing NKp46+ cells. Nat Immunol. 2009; 10:83-91. [PubMed: 19029903]

18. Falck J, Coates J, Jackson SP. Conserved modes of recruitment of ATM, ATR and DNA-PKcs to sites of DNA damage. Nature. 2005; 434:605-611. DOI: 10.1038/nature03442 [PubMed: 15758953]

19. Barry SP, et al. STAT3 modulates the DNA damage response pathway. Int J Exp Pathol. 2010; 91:506-514. DOI: 10.1111/j.1365-2613.2010.00734.x [PubMed: 20804538]

20. Pickert G, et al. STAT3 links IL-22 signaling in intestinal epithelial cells to mucosal wound healing. J Exp Med. 2009; 206:1465-1472. [PubMed: 19564350]

21. Rogakou EP, Pilch DR, Orr AH, Ivanova VS, Bonner WM. DNA double-stranded breaks induce histone H2AX phosphorylation on serine 139. J Biol Chem. 1998; 273:5858-5868. [PubMed: 9488723]

22. Fischer M. Census and evaluation of p53 target genes. Oncogene. 2017; 36:3943-3956. DOI: 10.1038/onc.2016.502 [PubMed: 28288132]

23. Merritt AJ, et al. The role of p53 in spontaneous and radiation-induced apoptosis in the gastrointestinal tract of normal and p53-deficient mice. Cancer Res. 1994; 54:614-617. [PubMed: 8306319]

24. Qiu W, et al. PUMA regulates intestinal progenitor cell radiosensitivity and gastrointestinal syndrome. Cell Stem Cell. 2008; 2:576-583. DOI: 10.1016/j.stem.2008.03.009 [PubMed: 18522850]

25. Hernandez P, Gronke K, Diefenbach A. A catch-22: Interleukin-22 and cancer. Eur J Immunol. 2018; 48:15-31. DOI: 10.1002/eji.201747183 [PubMed: 29178520]

26. Schumacher F, et al. A secondary metabolite of Brassicales, 1-methoxy-3-indolylmethyl glucosinolate, as well as its degradation product, 1-methoxy-3-indolylmethyl alcohol, forms DNA adducts in the mouse, but in varying tissues and cells. Arch Toxicol. 2014; 88:823-836. DOI: 10.1007/s00204-013-1149-7 [PubMed: 24154822]

27. Kiss EA, et al. Natural aryl hydrocarbon receptor ligands control organogenesis of intestinal lymphoid follicles. Science. 2011; 334:1561-1565. DOI: 10.1126/science.1214914 [PubMed: 22033518] 
28. Li Y, et al. Exogenous Stimuli Maintain Intraepithelial Lymphocytes via Aryl Hydrocarbon Receptor Activation. Cell. 2011; 147:629-640. DOI: 10.1016/j.cell.2011.09.025 [PubMed: 21999944]

29. Lee JS, et al. AHR drives the development of gut ILC22 cells and postnatal lymphoid tissues via pathways dependent on and independent of Notch. Nat Immunol. 2012; 13:144-151. DOI: 10.1038/ni.2187

30. Metidji A, et al. The Environmental Sensor AHR Protects from Inflammatory Damage by Maintaining Intestinal Stem Cell Homeostasis and Barrier Integrity. Immunity. 2018; 49:353-362 e355. DOI: 10.1016/j.immuni.2018.07.010 [PubMed: 30119997]

31. Eberl G, Littman DR. Thymic origin of intestinal alphabeta T cells revealed by fate mapping of RORgammat+ cells. Science. 2004; 305:248-251. [PubMed: 15247480]

32. Kreymborg K, et al. IL-22 is expressed by Th17 cells in an IL-23-dependent fashion, but not required for the development of autoimmune encephalomyelitis. J Immunol. 2007; 179:80988104. [PubMed: 18056351]

33. Alonzi T, et al. Essential role of STAT3 in the control of the acute-phase response as revealed by inducible gene inactivation [correction of activation] in the liver. Mol Cell Biol. 2001; 21:16211632. DOI: 10.1128/MCB.21.5.1621-1632.2001 [PubMed: 11238899]

34. el Marjou F, et al. Tissue-specific and inducible Cre-mediated recombination in the gut epithelium. Genesis. 2004; 39:186-193. DOI: 10.1002/gene.20042 [PubMed: 15282745]

35. Schmidt JV, Su GH, Reddy JK, Simon MC, Bradfield CA. Characterization of a murine Ahr null allele: involvement of the Ah receptor in hepatic growth and development. Proc Natl Acad Sci U S A. 1996; 93:6731-6736. [PubMed: 8692887]

36. Walisser JA, Glover E, Pande K, Liss AL, Bradfield CA. Aryl hydrocarbon receptor-dependent liver development and hepatotoxicity are mediated by different cell types. Proc Natl Acad Sci USA. 2005; 102:17858-17863. DOI: 10.1073/pnas.0504757102 [PubMed: 16301529]

37. Skarnes WC, et al. A conditional knockout resource for the genome-wide study of mouse gene function. Nature. 2011; 474:337-342. DOI: 10.1038/nature10163 [PubMed: 21677750]

38. Farley FW, Soriano P, Steffen LS, Dymecki SM. Widespread recombinase expression using FLPeR (flipper) mice. Genesis. 2000; 28:106-110. [PubMed: 11105051]

39. Gronke K, Kofoed-Nielsen M, Diefenbach A. Isolation and Flow Cytometry Analysis of Innate Lymphoid Cells from the Intestinal Lamina Propria. Methods Mol Biol. 2017; 1559:255-265. DOI: 10.1007/978-1-4939-6786-5_17 [PubMed: 28063049]

40. Cossarizza A, et al. Guidelines for the use of flow cytometry and cell sorting in immunological studies. Eur J Immunol. 2017; 47:1584-1797. DOI: 10.1002/eji.201646632 [PubMed: 29023707]

41. Schindelin J, et al. Fiji: an open-source platform for biological-image analysis. Nat Methods. 2012; 9:676-682. DOI: 10.1038/nmeth.2019 [PubMed: 22743772]

42. Trapnell C, et al. Transcript assembly and quantification by RNA-Seq reveals unannotated transcripts and isoform switching during cell differentiation. Nat Biotechnol. 2010; 28:511-515. DOI: 10.1038/nbt.1621 [PubMed: 20436464]

43. Subramanian A, et al. Gene set enrichment analysis: a knowledge-based approach for interpreting genome-wide expression profiles. Proc Natl Acad Sci U S A. 2005; 102:15545-15550. DOI: 10.1073/pnas.0506580102 [PubMed: 16199517]

44. Quaroni A, Wands J, Trelstad RL, Isselbacher KJ. Epithelioid cell cultures from rat small intestine. Characterization by morphologic and immunologic criteria. J Cell Biol. 1979; 80:248-265. [PubMed: 88453]

45. Takahashi M, Nakatsugi S, Sugimura T, Wakabayashi K. Frequent mutations of the beta-catenin gene in mouse colon tumors induced by azoxymethane. Carcinogenesis. 2000; 21:1117-1120. [PubMed: 10836998]

46. Schumacher F, Herrmann K, Florian S, Engst W, Glatt H. Optimized enzymatic hydrolysis of DNA for LC-MS/MS analyses of adducts of 1-methoxy-3-indolylmethyl glucosinolate and methyleugenol. Anal Biochem. 2013; 434:4-11. DOI: 10.1016/j.ab.2012.11.001 [PubMed: 23142629] 
47. Schumacher F, et al. Detection of DNA adducts originating from 1-methoxy-3-indolylmethyl glucosinolate using isotope-dilution UPLC-ESI-MS/MS. Anal Chem. 2012; 84:6256-6262. DOI: 10.1021/ac301436q [PubMed: 22816785]

48. Speckmann B, et al. Selenium increases hepatic DNA methylation and modulates one-carbon metabolism in the liver of mice. J Nutr Biochem. 2017; 48:112-119. DOI: 10.1016/j.jnutbio. 2017.07.002 [PubMed: 28810182] 
a

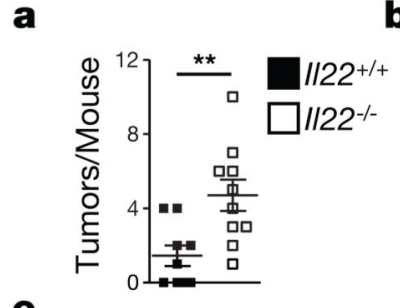

e

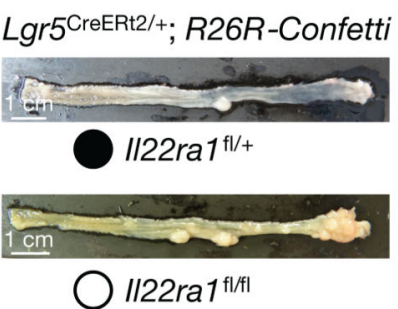

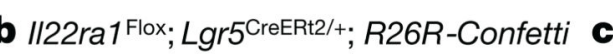

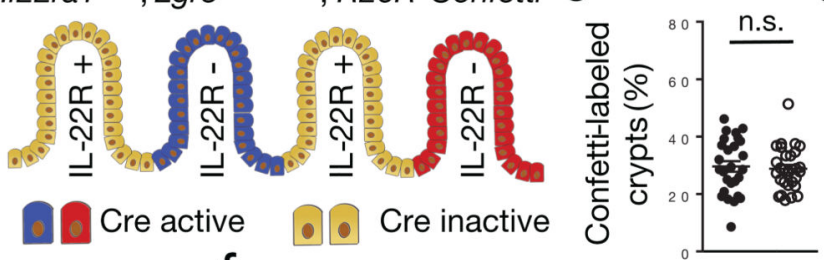

d

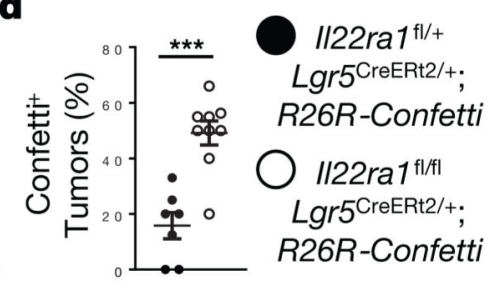

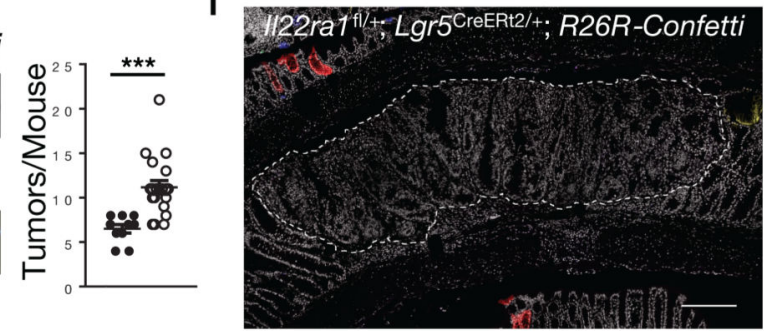

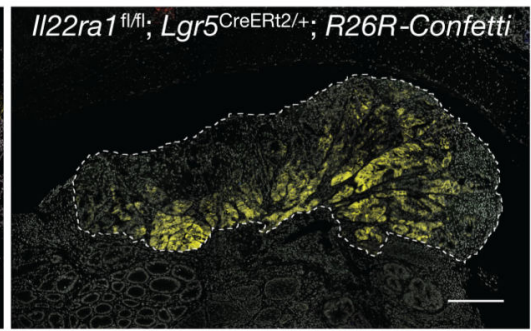

Figure 1. IL-22 protects stem cells against malignant transformation

(a) Colon tumors in mice injected with AOM only $\left(I I 22^{+/+} \mathrm{n}=9, I 122^{-/-} \mathrm{n}=10\right.$, mean $\pm \mathrm{SEM}$, $\mathrm{p}=0.0059)$.

(b-f) Indicated strains were treated 2 weeks with tamoxifen diets and subjected to AOM/ DSS. (b) Sporadic deletion of IL-22R after Cre activation. (c) Labeling efficiency (\%) of crypts (II22ra ${ }^{\mathrm{fl} /+} \mathrm{n}=27, I I 22 \mathrm{ra} I^{\mathrm{fl} / \mathrm{fl}} \mathrm{n}=29$ visual fields, mean $\left.\pm \mathrm{SEM}, \mathrm{p}=0.7256\right)$. (d) Fraction

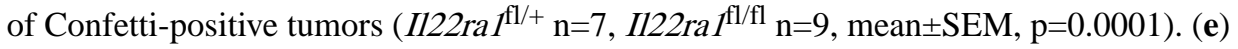
Quantification of all tumors $\left(I 122 \mathrm{raI}^{\mathrm{fl} /+} \mathrm{n}=10\right.$, II22ral $^{\mathrm{fl} / \mathrm{fl}} \mathrm{n}=19$, mean $\left.\pm \mathrm{SEM}, \mathrm{p}=0.0003\right)$. Scale bar $=1 \mathrm{~cm}$. (f) Representative immunohistology of colon carcinomas. Scale bar=200 $\mu \mathrm{m}$. Data are representative of two (a,d-f) and three (c) biologically independent experiments 

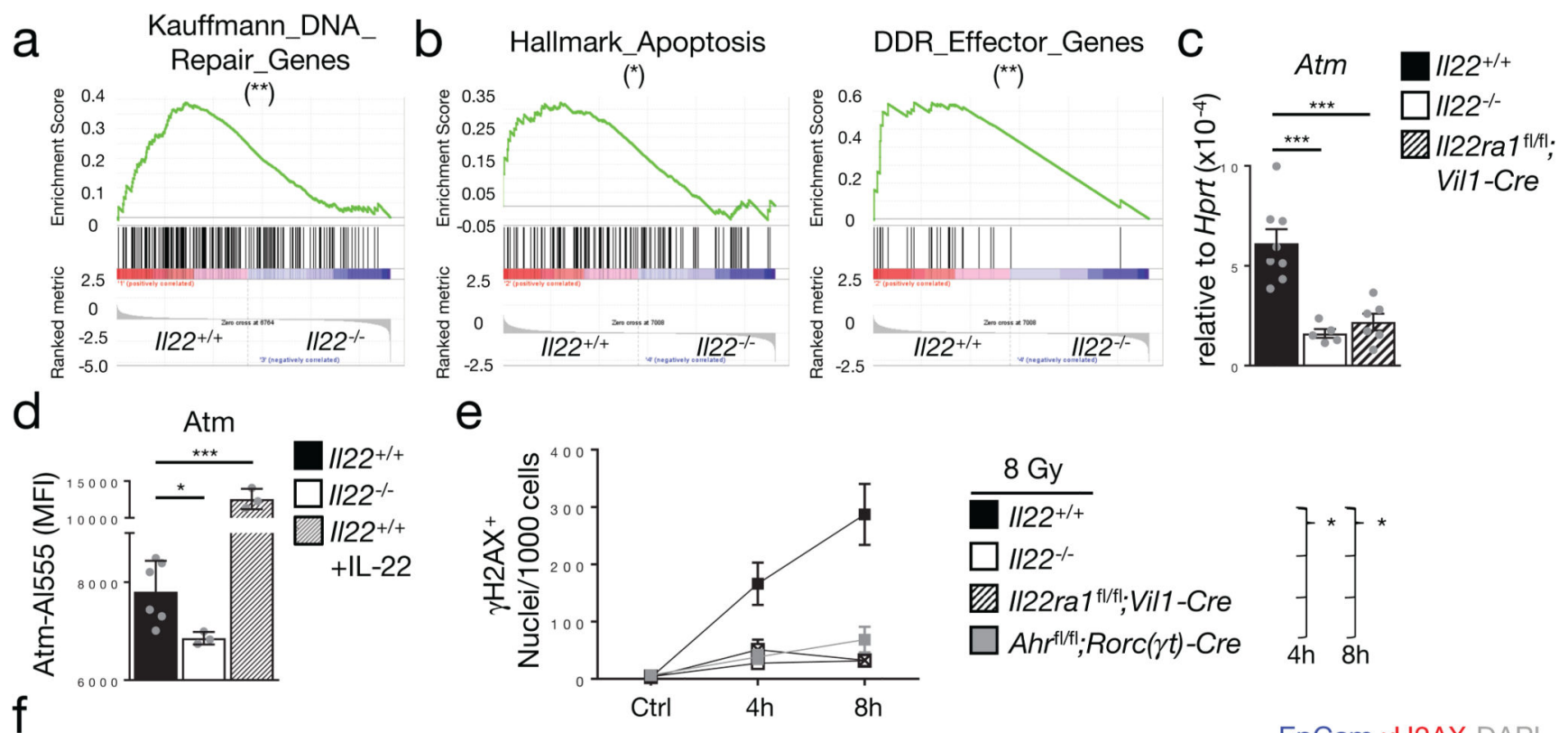

\section{e}
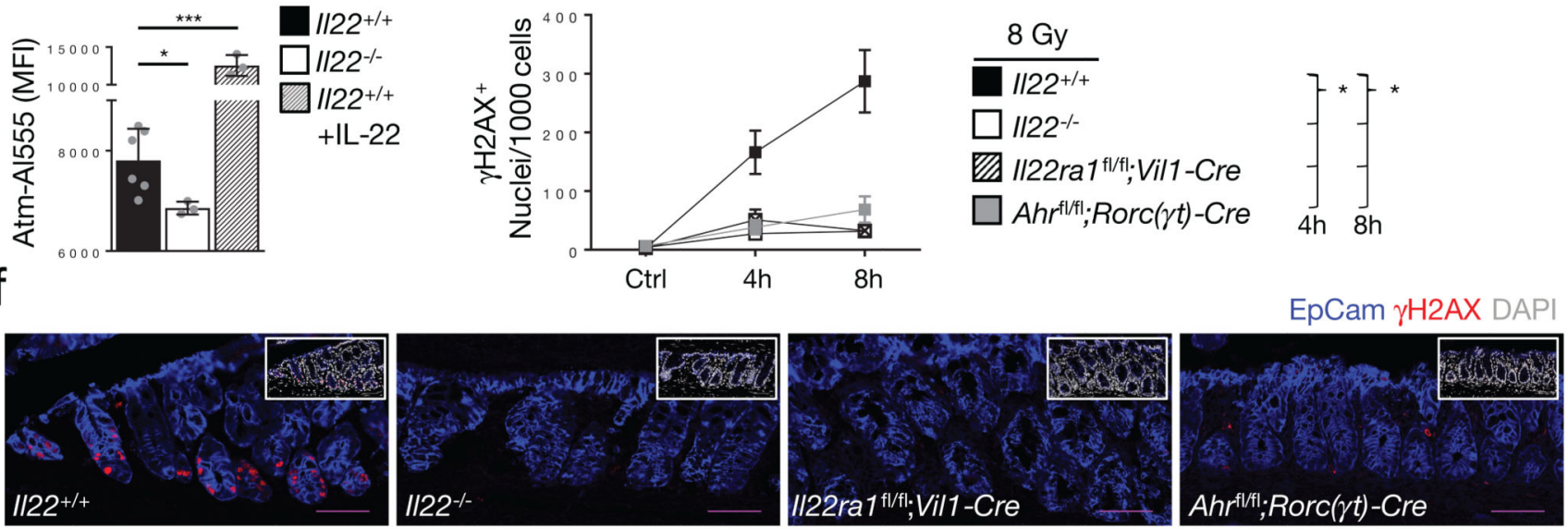

Figure 2. IL-22 regulates key components of the DDR

(a-b) $I 122^{+/+} ; L g r 5^{\text {Egfp/+ }}$ and $I 122^{-/} ; \operatorname{Lgr} 5^{\text {Egfp/+ }}$ mice $(\mathrm{n}=3)$ untreated (a) or irradiated with 8 Gy (b). Lgr5 (GFP)+ colon epithelial stem cells were purified. Gene expression was analyzed by RNA-seq. Gene set enrichment analysis (GSEA) on all expressed transcripts at steady-state (a) or $24 \mathrm{~h}$ after irradiation (b). Nominal p-value (Kolmogorov-Smirnov test) was calculated for Kauffmann_DNA_Repair_Genes ( $\mathrm{p}=0.009)$, Hallmark_Apoptosis $(\mathrm{p}=0.05)$, DDR_Effector_Genes $(\mathrm{p}=0.004)$.

(c) Atm gene expression in untreated colon epithelial stem cells determined by qRT-PCR

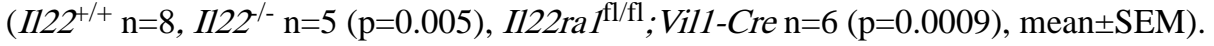

(d) ATM expression in untreated colon epithelial $\left(\mathrm{EpCam}^{+}\right)$cells or after IL-22 injection. MFI $\left(I I 22^{+/+} \mathrm{n}=6, I I 22^{/-} \mathrm{n}=3(\mathrm{p}=0.04), I I 22^{+/+}+\mathrm{IL}-22 \mathrm{n}=3(\mathrm{p}=0.0001)\right.$, mean \pm SEM $)$.

(e,f) Mice were irradiated with $8 \mathrm{~Gy} \cdot \gamma \mathrm{H} 2 \mathrm{AX}$ formation in colon epithelial (EpCam $\left.{ }^{+}\right)$cells 4 $\mathrm{h}$ and $8 \mathrm{~h}$ after irradiation. (e) Quantification of $\gamma \mathrm{H} 2 \mathrm{AX}^{+}$nuclei $\left(I 122^{+/+} 8 \mathrm{~h} \mathrm{n}=6\right.$, $A h r^{\mathrm{fl} / \mathrm{fl}} ; \operatorname{Rorc}(\gamma t)-C r e 8 \mathrm{~h} \mathrm{n}=7$, other $\mathrm{n}=3$, mean $\left.\pm \mathrm{SEM}\right)$. (f) Representative immunohistology 8 $\mathrm{h}$ after irradiation. Scale bar $=50 \mu \mathrm{m}$.

Data are representative of two (c-f) biologically independent experiments 


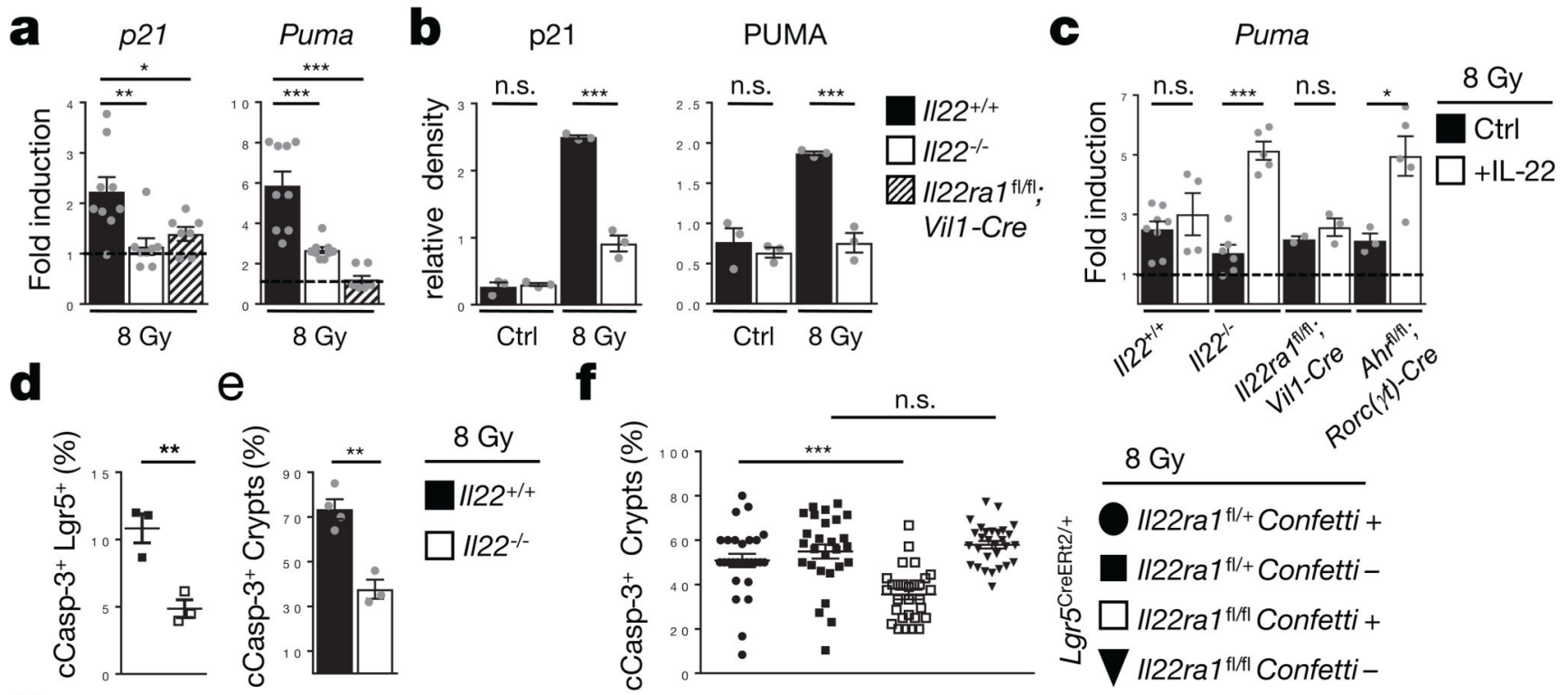

9
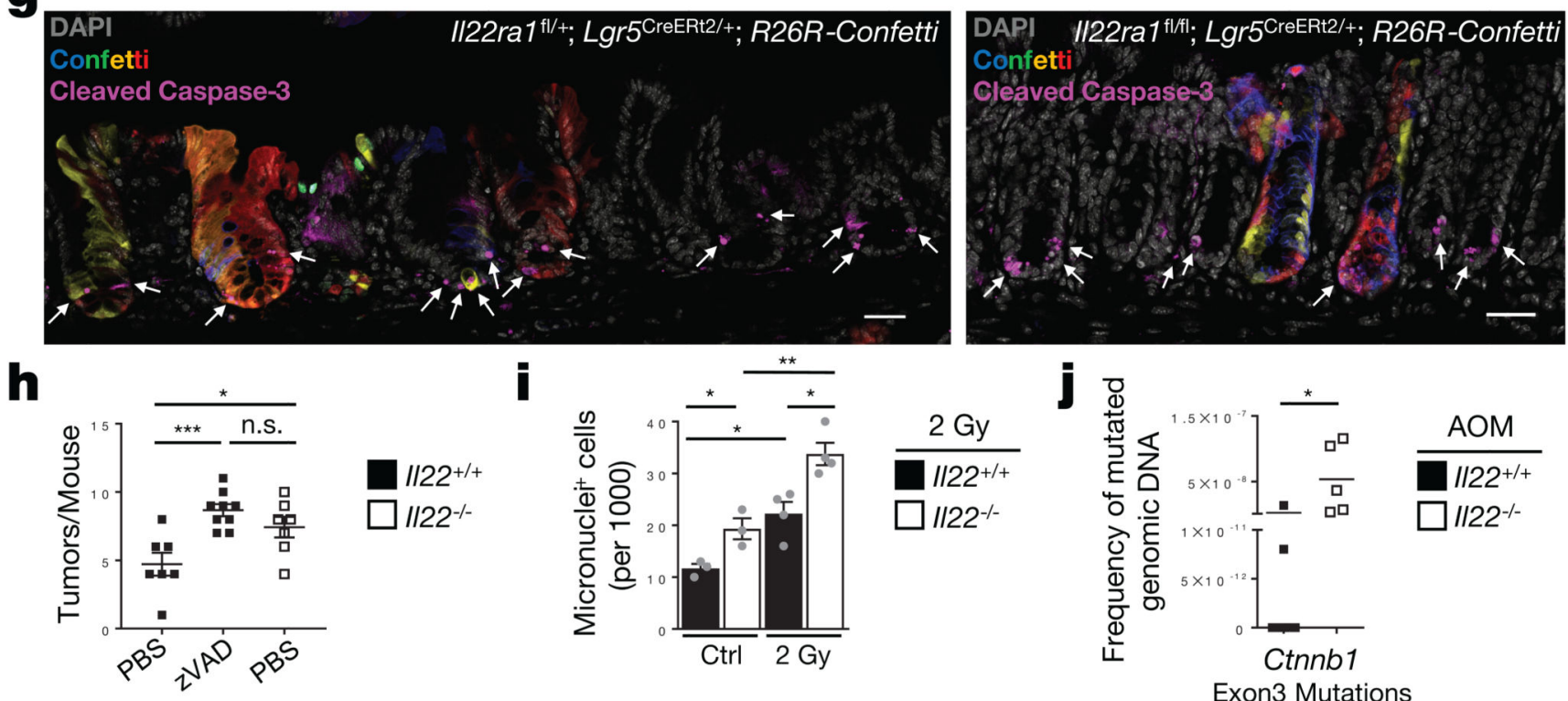

Figure 3. IL-22 controls DNA damage-induced apoptosis of colon stem cells

(a-g) Mice were irradiated with 8Gy. (a) Fold induction of p21 and Puma gene expression.

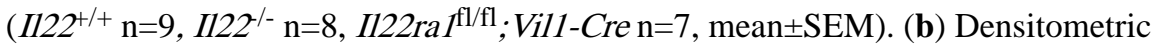

quantification of indicated proteins in primary colon epithelium $24 \mathrm{~h}$ after irradiation $(\mathrm{n}=3$, mean \pm SEM). (c) Treatment with IL-22 or PBS prior to irradiation. Fold induction of Puma

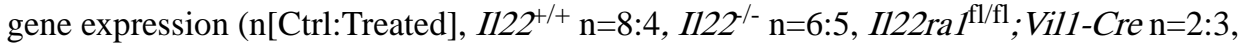
$A h r^{\mathrm{fl} / \mathrm{fl}} ; \operatorname{Rorc}(\gamma t)-C r e \mathrm{n}=3: 5$, mean $\left.\pm \mathrm{SEM}\right)$. (d) Percentage of cCasp- $3^{+}$Lgr5 ${ }^{+}$cells determined by flow cytometry $(n=3$, mean \pm SEM, $p=0.0092)$. (e) Percentage of cCasp- $3^{+}$ crypts $\left(I 122^{+/+} \mathrm{n}=4, I 122^{/-} \mathrm{n}=3\right.$, mean \pm SEM, $\left.\mathrm{p}=0.0024\right)$.

$(\mathbf{f}, \mathbf{g})$ Indicated lines were fed for two weeks with tamoxifen diets and subsequently irradiated. (f) Percentage of cCasp- $3^{+}$crypts (II22ra $I^{\mathrm{fl} /+} \mathrm{n}=27, I 122 \mathrm{ra} I^{\mathrm{fl} / \mathrm{fl}} \mathrm{n}=29$ visual fields, 
mean \pm SEM). (g) Representative images $8 \mathrm{~h}$ after irradiation (arrows indicate apoptotic cells). Scale bar $=30 \mu \mathrm{m}$.

(h) Indicated mice were treated with AOM/DSS and pan-caspase inhibitor (zVAD). Quantification of tumors at day $90\left(I I 22^{+/+} \mathrm{n}=7, I 122^{+/+}+\mathrm{zVAD} \mathrm{n}=9 \mathrm{II22^{-/ }} \mathrm{n}=7\right.$, mean \pm SEM).

(i) Mice were untreated or irradiated with 2Gy. Colon epithelial cells were isolated $48 \mathrm{~h}$ later. Cells containing one or more micronuclei were quantified $(\mathrm{Ctrl} n=3$, irradiated $n=4$, mean \pm SEM).

(j) Mice received three doses of AOM in weekly intervals. Genomic DNA was isolated from colon epithelial cells on day 75. Frequency of three common mutations in exon 3 of the Ctnnb1 gene determined by castPCR $\left(I I 22^{+/+} \mathrm{n}=7, I 122^{/-} \mathrm{n}=5\right.$, mean, $\left.\mathrm{p}=0.027\right)$.

Data are representative of two $(\mathbf{c}, \mathbf{f}-\mathbf{j})$, three $(\mathbf{b}, \mathbf{d}, \mathbf{e})$ or five $(\mathbf{a})$ biologically independent experiments. 

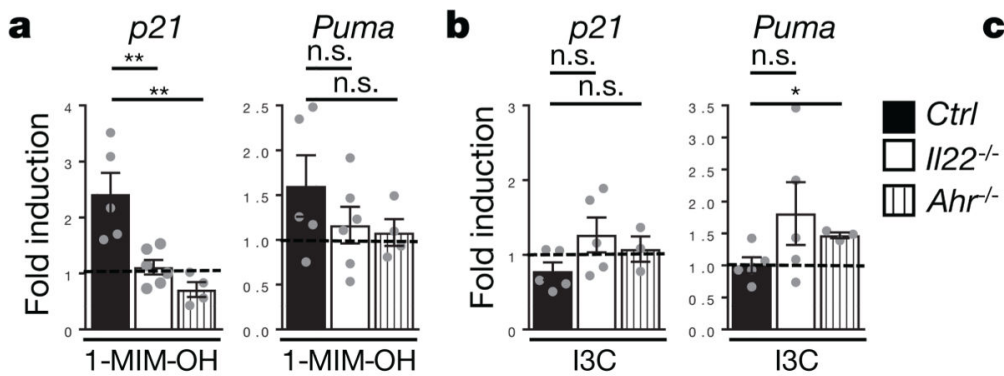

c $\quad \mathrm{CD}^{+} \mathrm{T}$ cell $\quad \gamma \delta \mathrm{T}$ cell ILC3

d $\mathrm{CD} 4^{+} \mathrm{T}$ cell $\gamma \delta \mathrm{T}$ cell ILC3
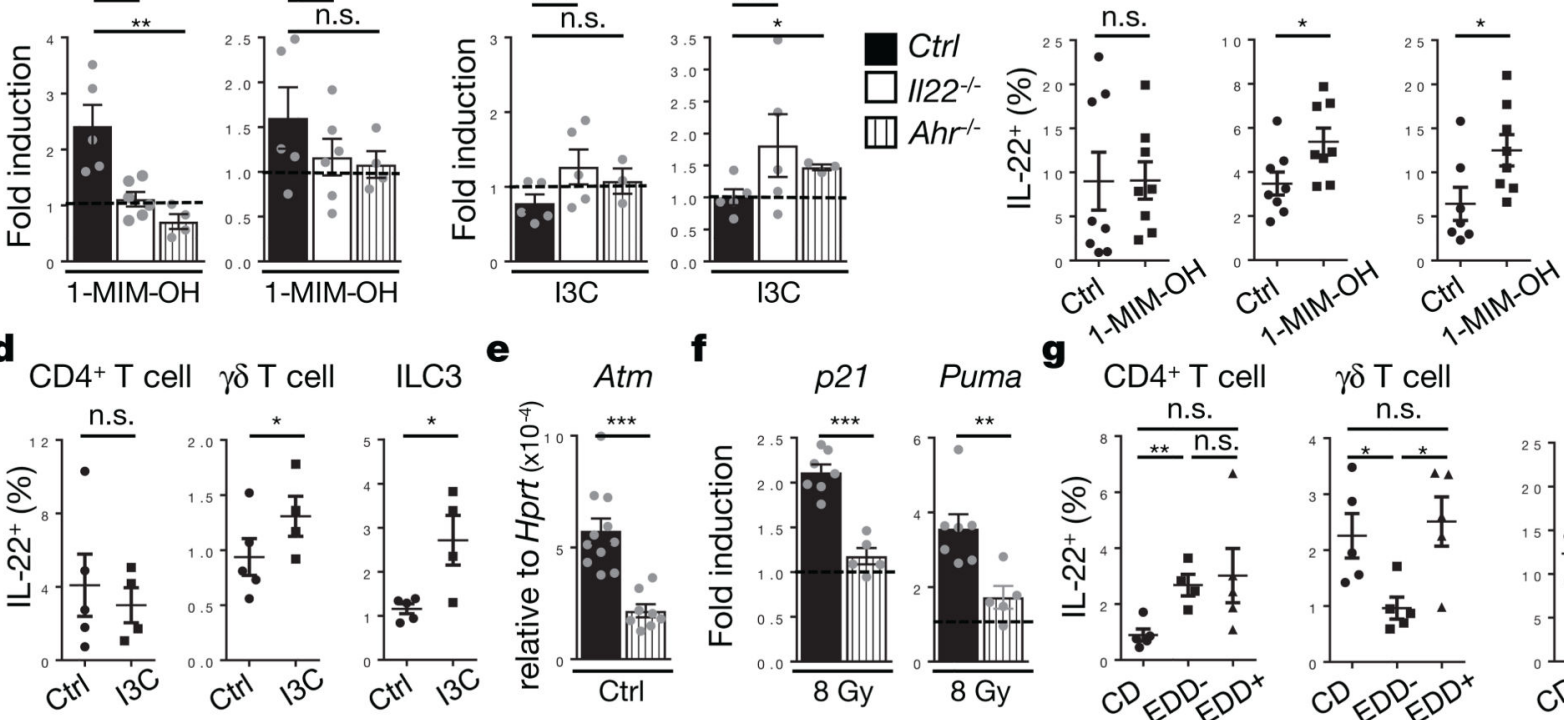

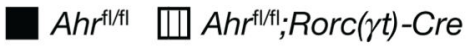
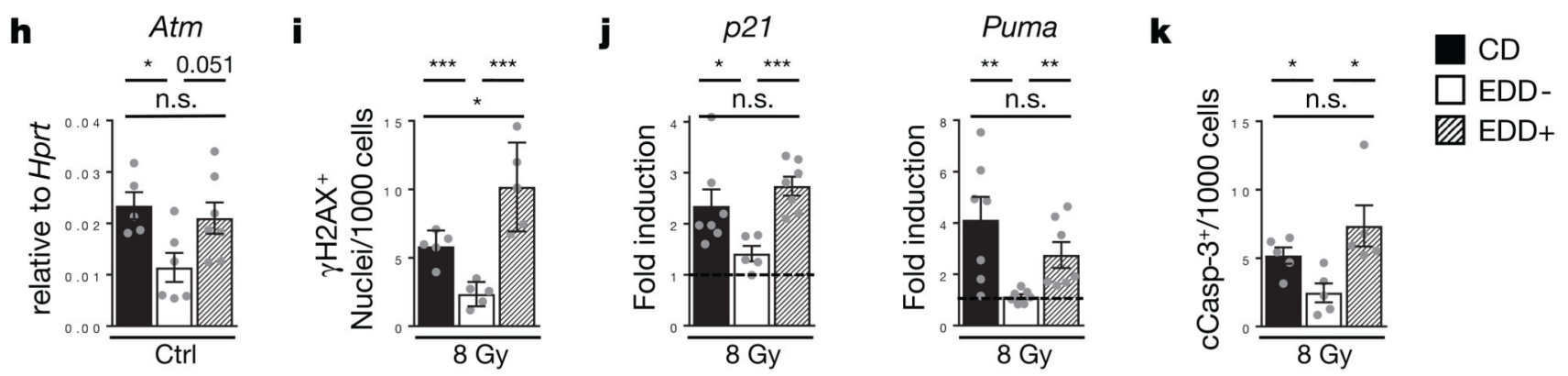

Figure 4. Dietary AhR ligands control IL-22 production and the DDR

(a-d) Mice received either 1-MIM-OH, I3C or Corn Oil (Ctrl) per gavage and were analyzed after 8h. (a,b) Fold induction of p21 and Puma gene expression in colon epithelial cells (Ctrl $\mathrm{n}=5, I I 22^{--} \mathrm{n}=6, A h r^{-/-} \mathrm{n}=4$, mean \pm SEM). (c,d) Percentage of IL-22 ${ }^{+}$cells among indicated lymphocyte subsets. ((c) $\mathrm{n}=8,(\mathbf{d}) \mathrm{n}=5$, mean \pm SEM).

(e-f) Gene expression in colon epithelial cells (e) of $A t m$ at steady state $\left(A h r^{\mathrm{fl} / \mathrm{fl}} \mathrm{n}=11\right.$, $A h r^{\mathrm{fl} / \mathrm{fl}} ; \operatorname{Rorc}(\gamma t)-C r e \mathrm{n}=8$, mean $\left.\pm \mathrm{SEM}, \mathrm{p}<0.0001\right)(\mathbf{f})$ of $p 21$ and Puma after $24 \mathrm{~h}\left(A h r^{\mathrm{fl} / \mathrm{fl}}\right.$ $\mathrm{n}=7, A h r^{\mathrm{fl} / \mathrm{fl}} ; \operatorname{Rorc}(\gamma t)-\operatorname{Cre} \mathrm{n}=5$, mean $\left.\pm \mathrm{SEM}\right)$.

(g-k) Mice were fed 6 weeks with the indicated diets. (g) Percentage of IL-22 ${ }^{+}$cells among indicated lymphocyte subsets (n=5, mean \pm SEM). (h) Atm gene expression in colon epithelial cells at steady-state. (CD n=5, EDD- n=6, EDD+ n=7, mean \pm SEM). (i-k) Diettreated mice were irradiated with $8 \mathrm{~Gy}$. Quantification of $\gamma \mathrm{H} 2 \mathrm{AX}^{+} \mathrm{EpCam}^{+}(\mathbf{i})$ and cCasp- $3^{+}$EpCam $^{+}$cells $(\mathbf{k}) 8 \mathrm{~h}$ after irradiation $(\mathrm{n}=5$, mean $\pm \mathrm{SEM})$. (j) Fold induction of $p 21$ and Puma gene expression in colon epithelial cells after $24 \mathrm{~h}(\mathrm{n}=7$, mean \pm SEM).

Data are representative of two (a-d and $\mathbf{i}-\mathbf{k})$ and three $(\mathbf{e}-\mathbf{h})$ biologically independent experiments. 